\title{
Primary Amine Tethered Small Molecules Promote the Degradation of X-Linked Inhibitor of Apoptosis Protein
}

Willem den Besten ${ }^{\mathrm{a}, \mathrm{f}}$, Kshitij Verma ${ }^{\mathrm{b}, \mathrm{f}}$, Sayumi Yamazoe ${ }^{\mathrm{b}}$, Nicole Blaquiere ${ }^{\mathrm{b}}$, Wilson Phung ${ }^{\mathrm{c}}$, Anita IzraelTomasevic c, Melinda M. Mulvihilld ${ }^{d}$, Elizabeth Helgason ${ }^{\mathrm{e}}$, Sumit Prakasha, Tatiana Goncharove ${ }^{\mathrm{e}}$, Domagoj Vucice, Erin Duebere, Wayne J. Fairbrother ${ }^{\mathrm{e}}$, Ingrid Wertz ${ }^{\mathrm{a}}$, Kebing $\mathrm{Yu}^{\mathrm{c}}$ and Steven T. Staben ${ }^{\mathrm{b}, *}$

Departments of a Discovery Oncology; ${ }^{b}$ Discovery Chemistry; ${ }^{C}$ Microchemistry Proteomics and Lipidomics; ${ }^{d}$ Biochemical and Cellular Pharmacology; ${ }^{e}$ Early Discovery Biochemistry at Genentech, Inc. 1 DNA Way, South San Francisco, CA 94080

${ }^{\ddagger}$ These authors contributed equally to this work 
Table of contents

\section{Supplementary figures}

Figure S1

Figure S2

Figure S3

Figure $\mathrm{S4}$

Figure S5

Figure $\mathrm{S6}$

Figure S7

\section{Materials and Methods}

2.1 Reagents

2.3 SPR analysis

2.4 Cell culture

2.5 Transfection of XIAP mutants

2.6 Immunoblot analysis

2.7 Identification of ubiquitinated small-molecule species

2.8 Immunoprecipitation with magnetic TUBE's

2.9 Biolayer interferometry (BLI) assays

\section{Synthesis}

3.1 Scheme S1

3.2 General synthetic procedure

3.3 Experimental

3.4 Analytical spectra for compound $\mathbf{1 0}$ 


\section{Supplementary figures}

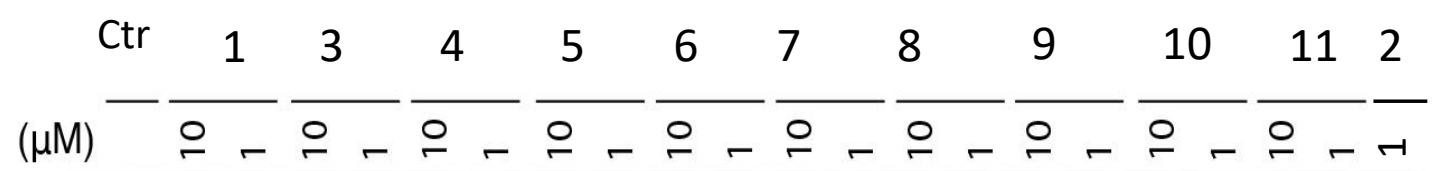

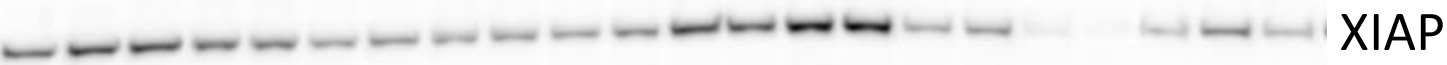

GAPDH

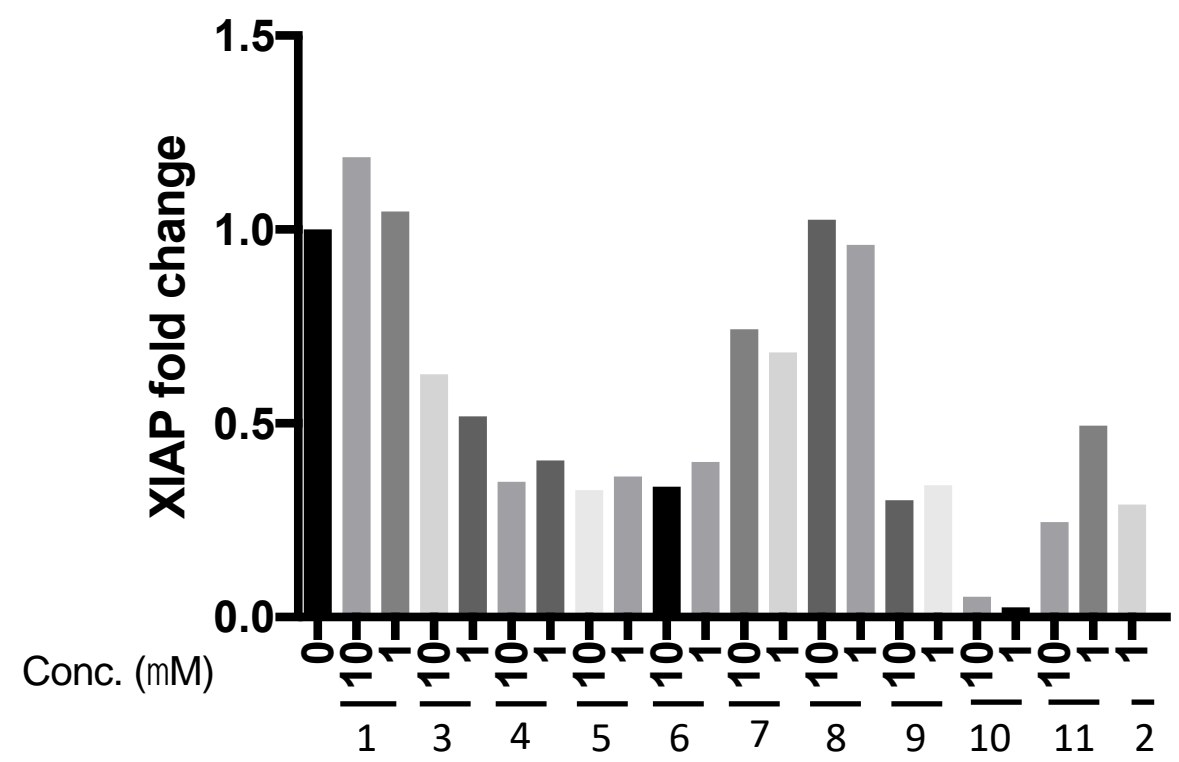

Figure S1. Compounds 1-11 promote variable XIAP degradation. XIAP expression levels were quantified, normalized to loading control and represented in the graph as fold-change in XIAP compared to the control. 
A.

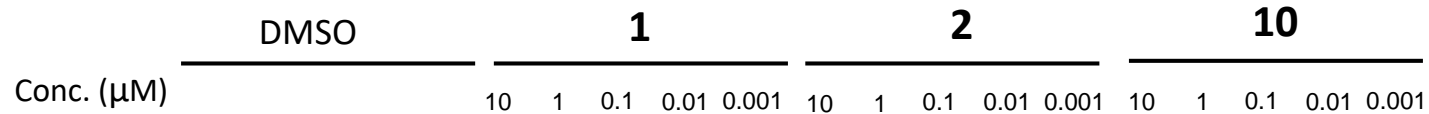

\section{$4 \mathrm{~h}$}

- - - - - - XIAP

$--1-1-1-1-1-1 \mathrm{GAPDH}$

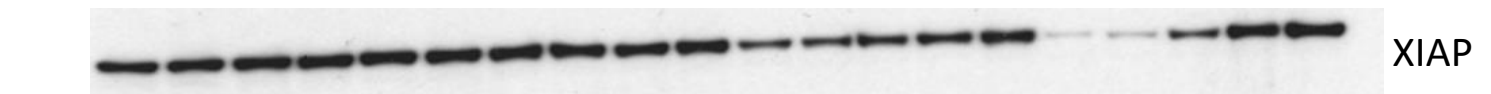

$16 \mathrm{~h}$

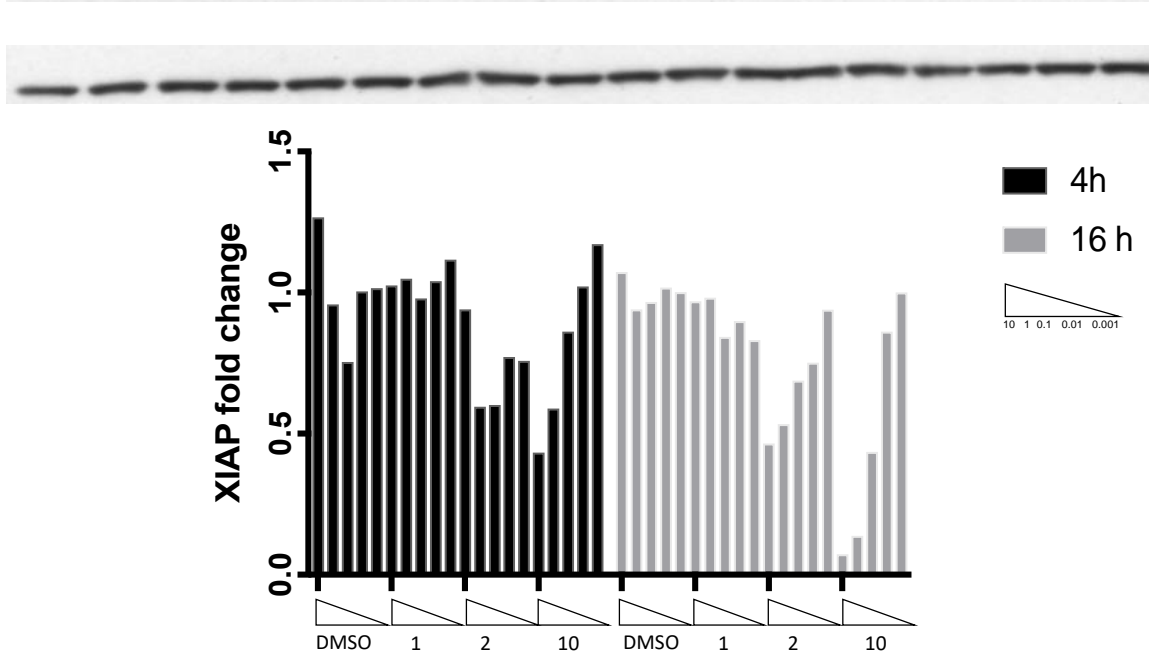

B.

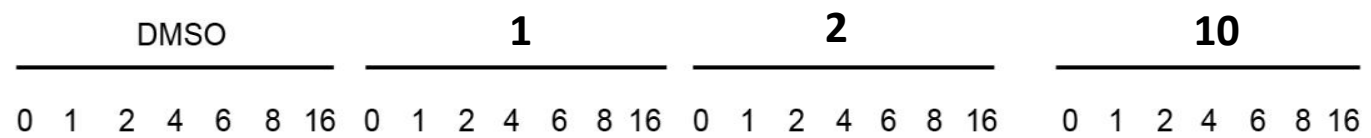

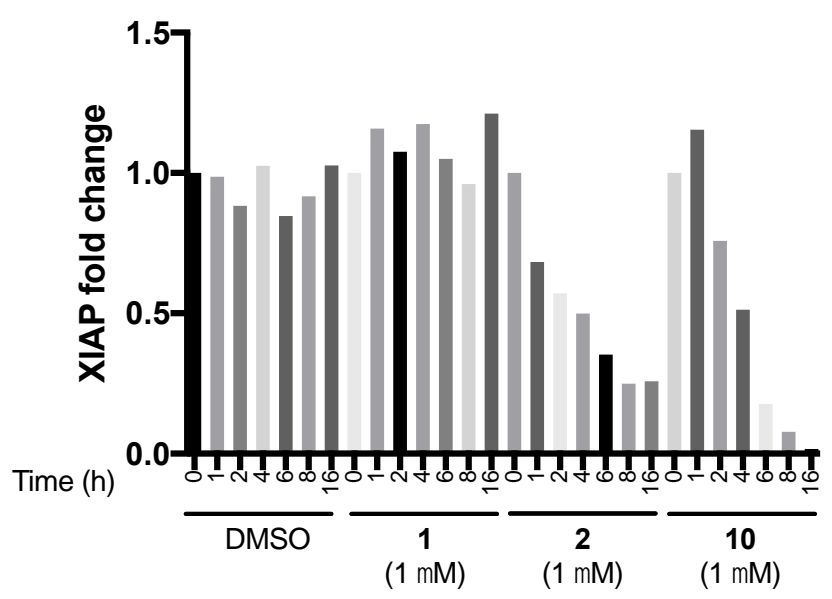

Figure S2. Concentration and time profile for XIAP degradation after treatment with compounds $\mathbf{1}, \mathbf{2}$ and $\mathbf{1 0}$. (A) Concentration dependent depletion of XIAP levels observed after treatment with $\mathbf{2}$ and $\mathbf{1 0}$ but not $\mathbf{1}$ at $4 \mathrm{~h}$ and 16h. (B) Time dependent depletion of XIAP expression observed after treatment with $\mathbf{2}$ and $\mathbf{1 0}$ but not $\mathbf{1}$ at 1 $\mu \mathrm{M}$ concentration. XIAP levels were quantified, normalized to loading control and represented in the graphs as fold-change in XIAP compared to the control. 
A.

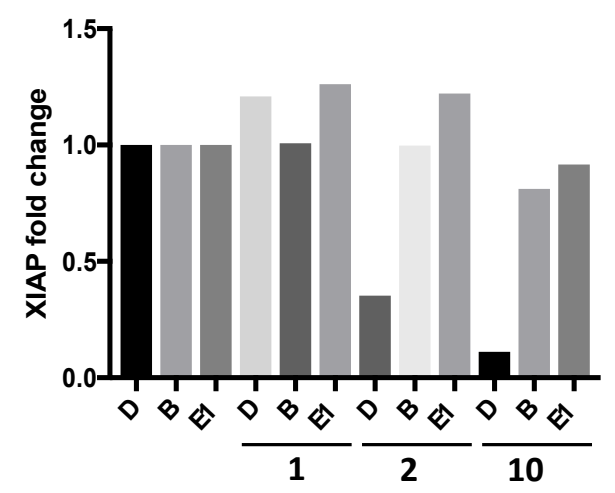

B.

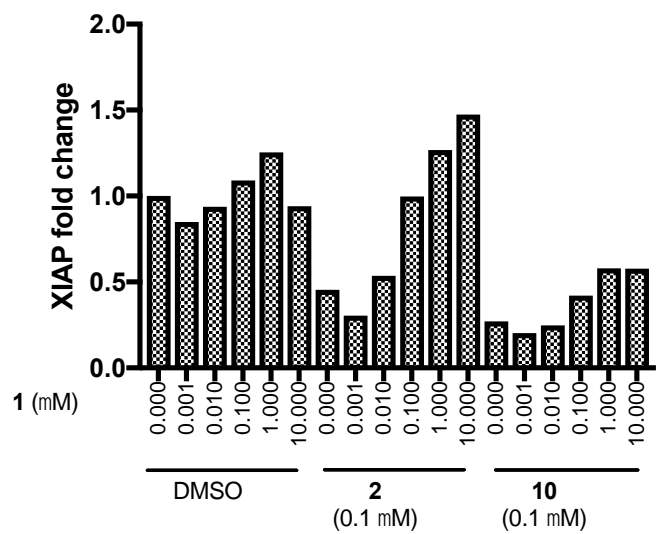

C.

\begin{tabular}{|c|c|c|c|c|c|c|c|c|}
\hline \multicolumn{3}{|c|}{ HA-XIAP V461E } & \multicolumn{3}{|c|}{ HA-XIAP F495A } & \multicolumn{3}{|c|}{ Empty vector } \\
\hline DMSO & & 10 & DMSO & 2 & 10 & DMSO & 2 & 10 \\
\hline
\end{tabular}
GAPDH XIAP

D.

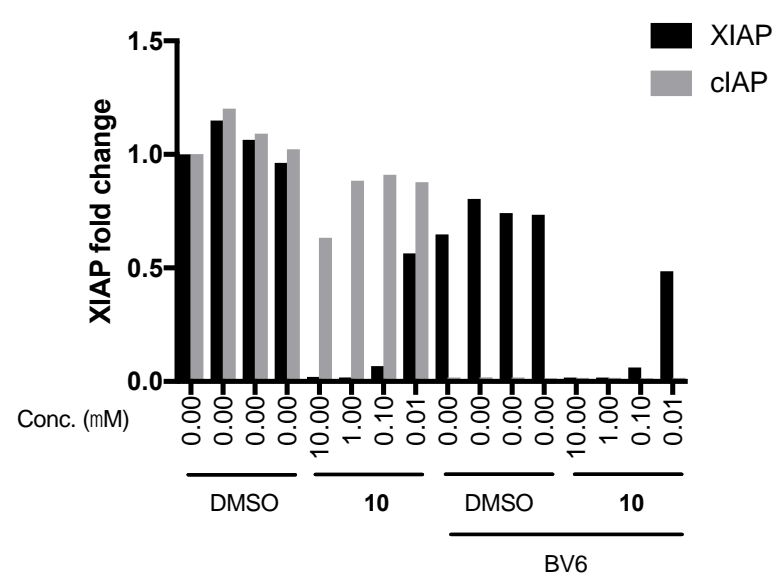

Figure S3. Degradation of XIAP by $\mathbf{2}$ and $\mathbf{1 0}$ is dependent on UPS and XIAP binding but is independent of XIAP dimerization and XIAP Ub activation. (A) Pretreatment with bortezomib or E1 inhibitor abrogates XIAP depletion in compounds 2 and 10. Quantification of blots expressed as fold-change in XIAP levels. (B) Competition with free BIR2 ligand (1) dose-dependently rescues XIAP levels in $\mathbf{2}$ and $\mathbf{1 0}$ treated groups. Quantification of blots expressed as fold-change in XIAP levels. (C) Degradation of XIAP induced by compounds $\mathbf{2}$ and $\mathbf{1 0}$ is not rescued by XIAP mutations -V461E (no dimerization) and -F495A (no Ub activation); 293T cells transfected with HAtagged XIAP-V461E or XIAP-F495A, $16 \mathrm{~h}$ treatment with indicated concentrations of test compounds. (D) Degradation of CIAP by BV6 has no effect on XIAP degradation promoted by 10. Quantification of blots expressed as fold-change in XIAP levels. 


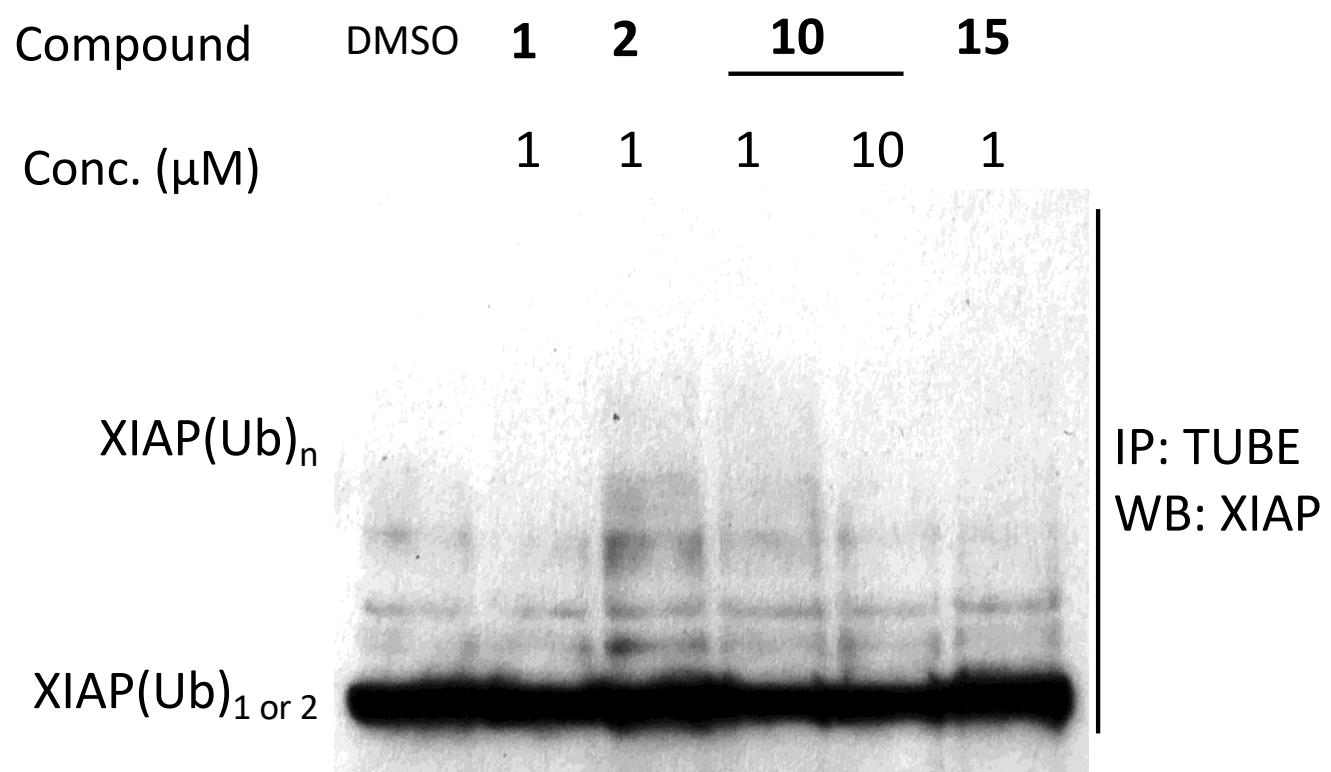

Figure S4. MCF-7 cell lysates after treatment with DMSO, 1, 2, 10 and 15 were subjected to TUBE pulldown and probed for XIAP. 


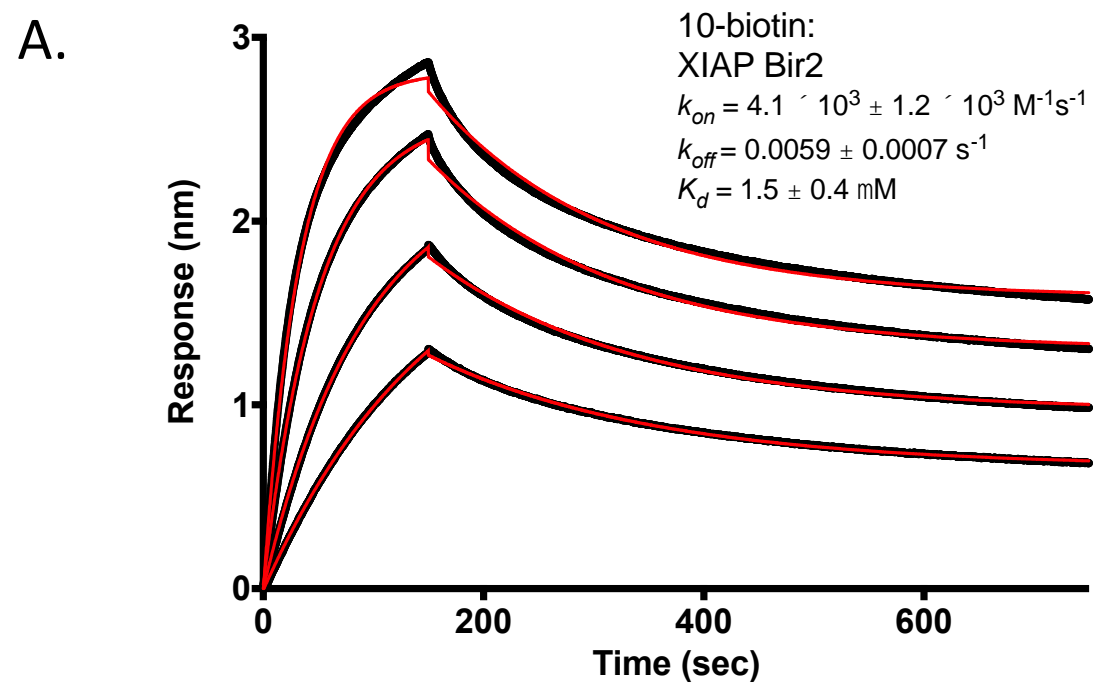

B.

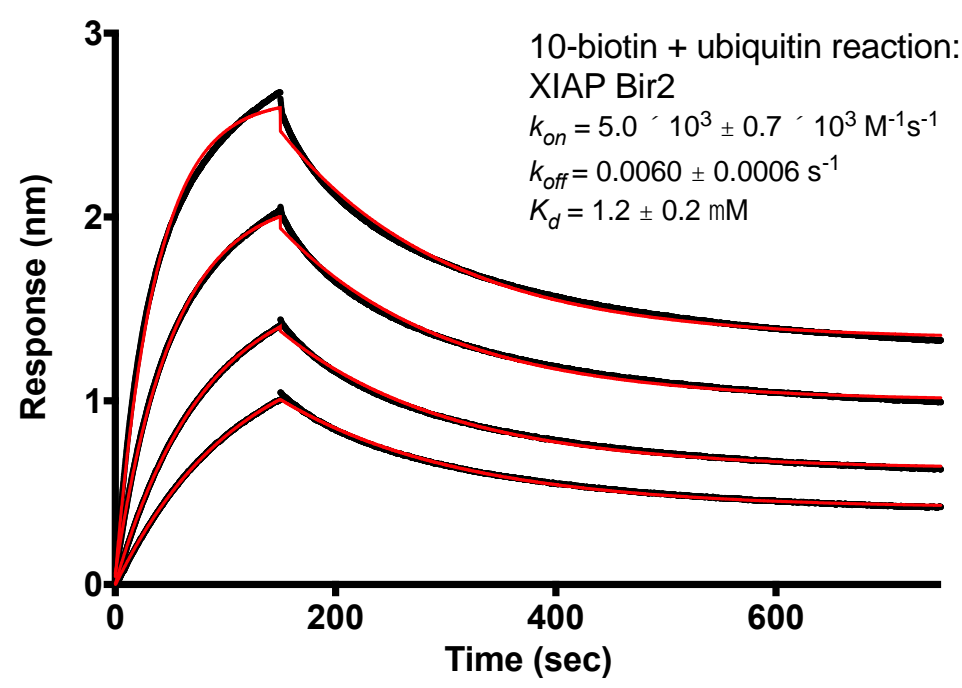

Figure S5. XIAP BIR2 binding kinetics to 10-biotin \pm ubiquitin reaction. (A) BLI sensograms are shown for XIAP BIR2 binding to 10-biotin or (B) 10-biotin + ubiquitination reaction. The 2-fold titration starts at $5 \mu$ M XIAP BIR2 and data was subtracted with a no loading control prior to fitting with a 1:1 binding model (red lines). Kinetic data is reported on each graph as an average of three technical replicates from four concentrations \pm standard deviation. 


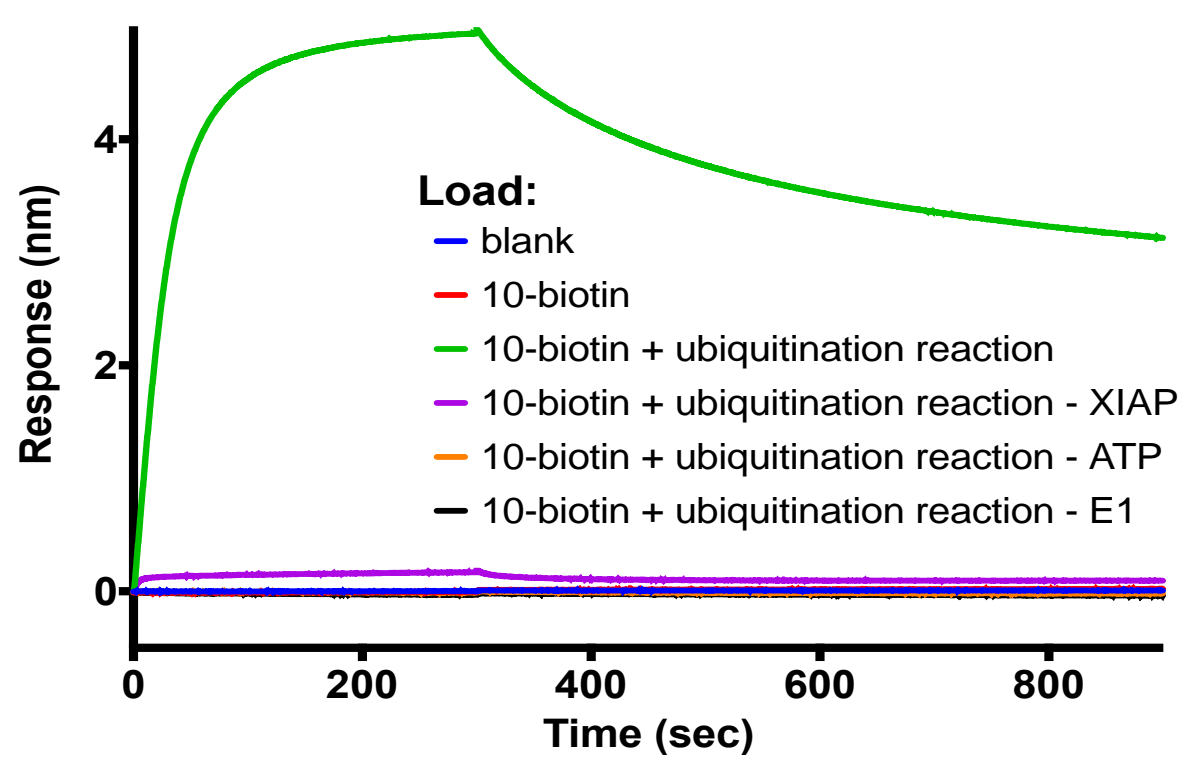

Figure S6. Detecting ubiquitin modification with BLI. 10-biotin was incubated in various ubiquitination reaction conditions (i.e. all required components or minus ubiquitination enzymes or ATP). The reactions were loaded on streptavidin sensor tips and washed. The BLI sensograms show the association and dissociation of the samples with the anti-ubiquitin antibody, UBCJ2. 


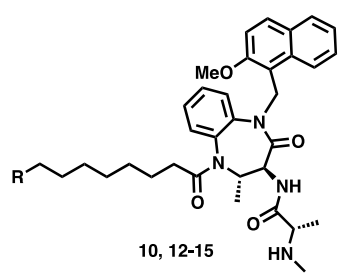

\begin{tabular}{lllll}
\hline Compound & $\mathbf{R}=$ & Degrader? & $\begin{array}{l}\text { XIAP BIR2 } \mathbf{K}_{\mathbf{d}} \\
(\mathrm{SPR})\end{array}$ & $\begin{array}{l}\text { XIAP fold } \\
\text { change }(10 \mu \mathrm{M})\end{array}$ \\
\hline 10 & $-\mathrm{NH}_{2}$ & YES & $24 \mathrm{nM}$ & 0.02 \\
12 & $-\mathrm{NHAC}$ & $\mathrm{NO}$ & $61 \mathrm{nM}$ & 1.2 \\
13 & $-\mathrm{NHC}(\mathrm{NH}) \mathrm{NH}_{2}$ & $\mathrm{NO}$ & $\mathrm{ND}$ & 1.1 \\
14 & $-\mathrm{NHMe}$ & $\mathrm{NO}$ & $\mathrm{ND}$ & 1.2 \\
15 & $-\mathrm{NMe}_{2}$ & $\mathrm{NO}$ & $54 \mathrm{nM}$ & 1.0 \\
\hline
\end{tabular}

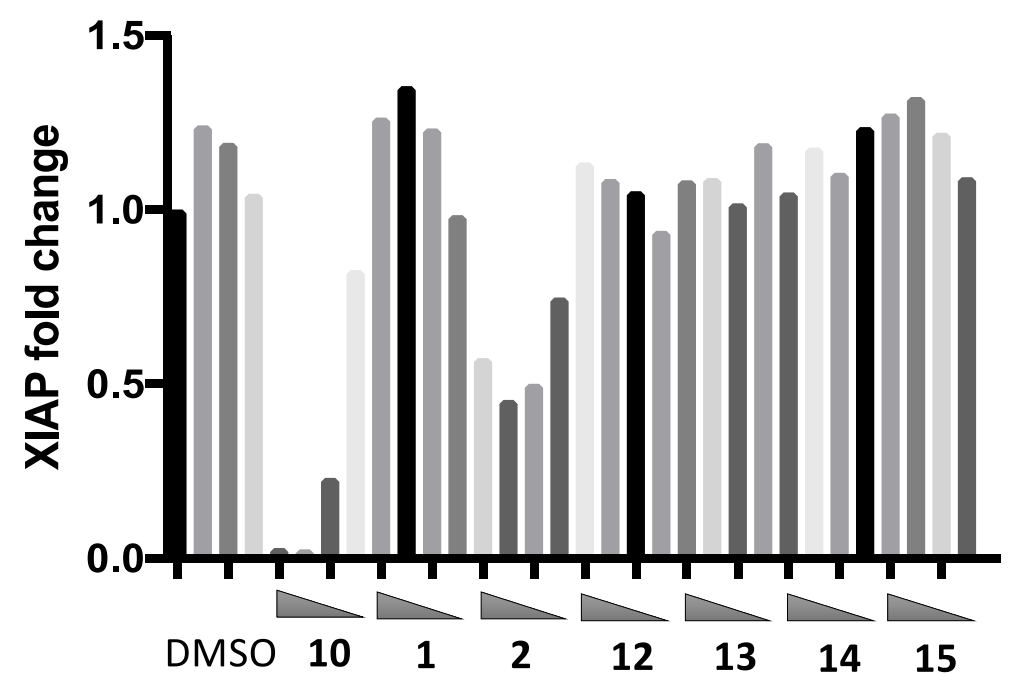

Figure S7. Compounds 12-15 do not promote degradation of XIAP. Graph represents the fold-change in XIAP after treatments with 10, 1, 2, 12-15 in MCF-7 cells compared to the control. Table showing compounds bearing modification of primary-amine tag and their respective binding affinity to XIAP BIR2 domain including fold change in XIAP at $10 \mu \mathrm{M}$ concentration. 


\section{Materials and methods}

\subsection{Reagents}

Bortezomib (2204S) was purchased from Cell Signaling technologies. E1 (ubiquitin activating enzyme) inhibitor TAK-243 (or MLN7243) (S8341) and BV6-a SMAC mimetic and dual XIAP/cIAP inhibitor (S7597) were purchased from Selleck Chemicals. UBE1 (or UBA1) (E-305), Ubc5a (or UBE2D1) (E2-616), XIAP (K-250), wt-ubiquitin (U$100 \mathrm{H}$ ) and Me-Ubiquitin (U-501) recombinant proteins were purchased from Boston Biochem (now R\&D Systems). Goat anti-human/mouse/rat XIAP polyclonal antibody (AF8221) and goat anti-human cIAP-1/HIAP-2 polyclonal antibody (AF8181) were purchased from R\&D systems. GAPDH rabbit mAb (HRP conjugate) (3683) was purchased from Cell Signaling technologies.

\subsection{Surface Plasmon Resonance (SPR)}

SPR experiments were performed on a Biacore T200 or S200 instrument. XIAP BIR2 (T152-N236, C202A, C213G) was biotinylated through an N-terminal Avi-tag and immobilized on a neutravidin (Thermo, 31000) coated C1 sensor chip (Biacore). The running buffer contained 50mM HEPES, pH 7.2, $150 \mathrm{mM} \mathrm{NaCl}, 0.001 \%$ Tween-20, 5 mM DTT, 0.2\% PEG 3350, and 2\% DMSO. Compounds were tested in 6-point dose response and concentrations were adjusted between $5 \mathrm{nM}$ to $50 \mu \mathrm{M}$ depending on potency. The contact time varied between 30 and $60 \mathrm{sec}$ and the dissociation time between 30 and $600 \mathrm{sec}$. Data was fit to a Kinetic 1:1 Binding Model in Biacore Evaluation software.

\subsection{Cell culture}

Experiments were performed using MCF-7 breast cancer cells, obtained from Genentech in-house repository and cultured in RPMI 1640 media supplemented with 10\% FBS (Sigma F2442), 1x GlutaMAX ${ }^{\mathrm{TM}}$ (Gibco 35050061), 1x Penicillin-Streptomycin (Gibco 15140-122). Cells were maintained at $37^{\circ} \mathrm{C}$ in $5 \% \mathrm{CO}_{2}$ atmosphere in a humidified incubator.

\subsection{Transfection of XIAP mutants}

The expression vectors pBABEpuro (Cell Biolabs, Inc.) HA tagged XIAP wt, XIAP F495A and XIAP V461E were generated by LakePharma. Expression vector pBABEpuro HA-tagged XIAP H467A was generated using the Q5 site-directed mutagenesis kit (New England Biolabs) with the following primers (sense: TCCTTGTGGAGCTCTAGTCACTTGTAAAC), (antisense: ACAAAAACGATAGCAATATTTC) according to the manufacturer's instructions. $10 \mu \mathrm{g}$ plasmids were added to Opti-MEM ${ }^{\mathrm{TM}}$ serum free media followed by addition of FuGENE ${ }^{\circledR}$ HD Transfection Reagent (E2311) and incubated for $15 \mathrm{~min}$. The media was applied to 293T cells and incubated overnight. Compound treatments were made in complete growth RPMI 1640 media overnight and cells were lysed for immunoblot analysis.

\subsection{Immunoblot analysis}

Cells were seeded into 12 -well plates at a density of $0.2 \times 10^{6}$ cells/well $(1 \mathrm{ml} /$ well). After overnight incubation, cells were treated with either DMSO $(0.1 \%)$, bortezomib $(5 \mu \mathrm{M})$, E1 inhibitor $(5 \mu \mathrm{M})$, BV6 $(1 \mu \mathrm{M})$ or compounds (DMSO stocks) at indicated concentration and time points. Cells were lysed in $6 \mathrm{M}$ urea buffer (20 mM Tris pH 7.5, $6 \mathrm{M}$ Urea, $0.1 \%$ Triton X-100, $12.5 \mathrm{mM} \mathrm{NaCl}$ and $2.5 \mathrm{mM} \mathrm{MgCl}_{2}$ ) supplemented with Roche protease inhibitor cocktail, centrifuged at $14000 \mathrm{rpm}$ and supernatant collected. Cell lysates were estimated for total protein content using Pierce ${ }^{\mathrm{TM}}$ BCA Protein Assay Kit (23225). Cell lysates were prepared in LDS sample buffer and sample reducing agent (Invitrogen). Equal amounts of proteins were resolved on SDS-PAGE gels (NuPAGE 4-12\% bis-tris) and transferred to nitrocellulose membranes. Following blocking (5\% non-fat dry milk in TBS with $0.1 \%$ tween 20), membranes were incubated with anti-XIAP antibody (1:500), anti-clAP1 antibody (1:1000) or antiGAPDH antibody (1:1000) in blocking buffer (1\% non-fat dry milk in TBS with $0.1 \%$ tween 20 ) overnight at $4^{\circ} \mathrm{C}$. Membranes were washed four times with TBST buffer and incubated with anti-goat secondary antibody-HRP (1:1000) in blocking buffer for $1 \mathrm{hr}$ at RT. Following membrane wash four times with TBST, chemiluminescence 
was developed using SuperSignal West Pico Chemiluminescent Substrate (ThermoFisher, $5 \mathrm{~mL}$ ) and protein bands were imaged on a ChemiDoc Imaging System (BioRad).

\subsection{Identification of ubiquitylated small-molecule species}

To a reaction buffer containing $30 \mathrm{mM}$ Tris pH 7.6 (Genentech), $50 \mathrm{mM} \mathrm{MgCl}$ (Genentech), $20 \mathrm{mM} \mathrm{DTT} \mathrm{(Sigma),}$ $20 \mathrm{mM}$ ATP (Sigma), $100 \mathrm{mM} \mathrm{NaCl}$ (Genentech) in $\mathrm{H}_{2} \mathrm{O}$ was added $1 \mu \mathrm{M}$ UBE1, $5 \mu \mathrm{M}$ UbcH5a, $1 \mu \mathrm{M}$ XIAP (Genentech), $100 \mu \mathrm{M}$ wt-Ub or Me-Ub and $1 \mu \mathrm{M} 10$ or 10-TAMRA in the presence or absence of 1 . The reaction mix was incubated at RT at indicated time points and quenched by boiling in LDS sample buffer. The samples were loaded on NuPAGE SDS 4-12\% Bis-Tris gel and resolved in MOPS running buffer. The gel was imaged using Typhoon Gel and Blot Imaging System (absorption/emission maxima 555/580 nm). In another instance the reactions were subjected to an intact mass spectrometric analysis.

\section{LC-MS method}

Three $\mu \mathrm{g}$ of each reaction sample were injected onto a MAbPac RPLC column $(2.1 \mathrm{~mm} \times 50 \mathrm{~mm}$, Thermo Fisher Scientific) heated to $80^{\circ} \mathrm{C}$ using an UltiMate 3000 RSLC system (Thermo Fisher Scientific). A binary gradient pump was used to deliver solvent A ( $99.88 \%$ water, $0.1 \%$ formic acid and $0.02 \%$ trifluoroacetic acid) and solvent B ( $90 \%$ acetonitrile, $9.88 \%$ water, $0.1 \%$ formic acid and $0.02 \%$ trifluoroacetic acid) as a gradient of $20 \%$ to $65 \%$ solvent B over $4.5 \mathrm{~min}$ at $300 \mu \mathrm{L} / \mathrm{min}$. The solvent was step-changed to $90 \%$ solvent B over $0.1 \mathrm{~min}$ and held at $90 \%$ for $6.4 \mathrm{~min}$ to clean the column. Finally, the solvent was step-changed to $20 \%$ solvent B over 0.1 min and held for $3.9 \mathrm{~min}$ for re-equilibration. Separated proteins were analyzed online via electrospray ionization into a Thermo Exactive Plus EMR Orbitrap mass spectrometer (Thermo Fisher Scientific) using the following optimized parameters for data acquisition: $3.90 \mathrm{kV}$ spray voltage; $325^{\circ} \mathrm{C}$ capillary temperature; $200 \mathrm{~S}$-lens RF level; 15 sheath gas flow rate and 4 AUX gas flow rate in ESI source; 300 to 4,500 m/z scan range; desolvation, in-source CID $100 \mathrm{eV}, \mathrm{CE}$ 0; resolution of 17,500 at m/z 200; positive polarity; 10 microscans; $3 \mathrm{E6}$ AGC target; fixed AGC mode; 0 averaging; $25 \mathrm{~V}$ source DC offset; $8 \mathrm{~V}$ injection flatapole DC; $7 \mathrm{~V}$ inter flatapole lens; $6 \mathrm{~V}$ bent flatapole DC; $0 \mathrm{~V}$ transfer multipole DC tune offset; $0 \mathrm{~V}$ C-trap entrance lens tune offset; and trapping gas pressure setting of 2. Acquired mass spectral data was analyzed using PMI Intact Mass software (Protein Metrics Inc.) with the following parameters: 1,000 to $4,500 \mathrm{~m} / \mathrm{z}$ range; 0.6 charge vectors spacing; $15 \mathrm{~m} / \mathrm{z}$ baseline radius; $0.02 \mathrm{~m} / \mathrm{z}$ smoothing sigma; $0.04 \mathrm{~m} / \mathrm{z}$ spacing; 3 mass smoothing sigma; 0.5 mass spacing; 10 iteration max; and 3 to 100 charge state range.

\subsection{Immunoprecipitation with magnetic Tandem Ubiquitin Binding Entities (TUBE)}

MCF-7 cells were treated with compounds $(\mathbf{1}, \mathbf{2}, \mathbf{1 0})$ and incubated for $3 \mathrm{~h}$. Cells were lysed in Pierce ${ }^{\mathrm{TM}}$ IP lysis buffer (87787) and total lysate protein was estimated using Pierce ${ }^{\mathrm{TM}}$ BCA Protein Assay Kit (23225). Magnetic TUBE beads (TUBE2, LifeSensors, UM402M) were washed with IP buffer three times and incubated with cell lysates (100 $\mu \mathrm{L}$ slurry per $1 \mathrm{mg}$ lysate) containing equal amounts of protein. Samples were put on a rotor for $3 \mathrm{~h}$ at RT. Supernatant was collected as unbound fraction, beads were washed with IP buffer three times and bound fraction was eluted by boiling in LDS sample buffer. Samples were resolved by SDS-PAGE on a 4-12\% Bis-Tris gel using MOPS buffer, transferred to PVDF membrane and blotted for XIAP.

\subsection{Biolayer interferometry (BLI) assays}

Assays were run on an Octet Red384 (ForteBio). For XIAP BIR2 binding assays, 10-biotin \pm ubiquitination reaction (30 mM Tris pH 7.6, $50 \mathrm{mM} \mathrm{MgCl}$, $20 \mathrm{mM} \mathrm{DTT,} 20 \mathrm{mM}$ ATP, $100 \mathrm{mM} \mathrm{NaCl}$ in $\mathrm{H}_{2} \mathrm{O}$ was added $1 \mu \mathrm{M}$ UBE1, $5 \mu \mathrm{M}$ UbcH5a, $1 \mu \mathrm{M}$ XIAP, $100 \mu \mathrm{M}$ wt-Ub and $2 \mu \mathrm{M}$ 10-biotin) was diluted to $200 \mathrm{nM}$ 10-biotin in Assay Buffer (AB: 20 $\mathrm{mM}$ HEPES, pH 7.2, $150 \mathrm{mM} \mathrm{NaCl}, 10 \%$ glycerol, $0.1 \mathrm{mM}$ TCEP, 0.05\% Tween-20, and $0.1 \mathrm{mg} / \mathrm{mL}$ BSA). After a $300 \mathrm{~s}$ load the tips were washed for 180 seconds prior to the $300 \mathrm{~s}$ association (XIAP BIR2 (R\&D Systems, 786XB) 2-fold dilution series: $0.63,1.25,2.5$, and $5 \mu \mathrm{M}$ ) and 600 s dissociation. Raw sensograms were subtracted with parallel reference sensors (no load) and fit with a 1:1 local partial model in the Fortebio Data Analysis 9.0 software. Data is reported based on three technical replicates of the four concentrations \pm standard deviations. 
For detecting ubiquitin modification, 10 -biotin \pm ubiquitination reactions (as above) \pm XIAP or ATP or E1 were diluted in $A B$ and loaded as above. The $300 \mathrm{~s}$ association was in a 1:24 dilution of the anti-ubiquitin antibody, UBCJ2 (Enzo, ENZ-ABS840), in AB. Raw sensograms were aligned to the baseline and plotted to show binding.

\section{Synthesis}

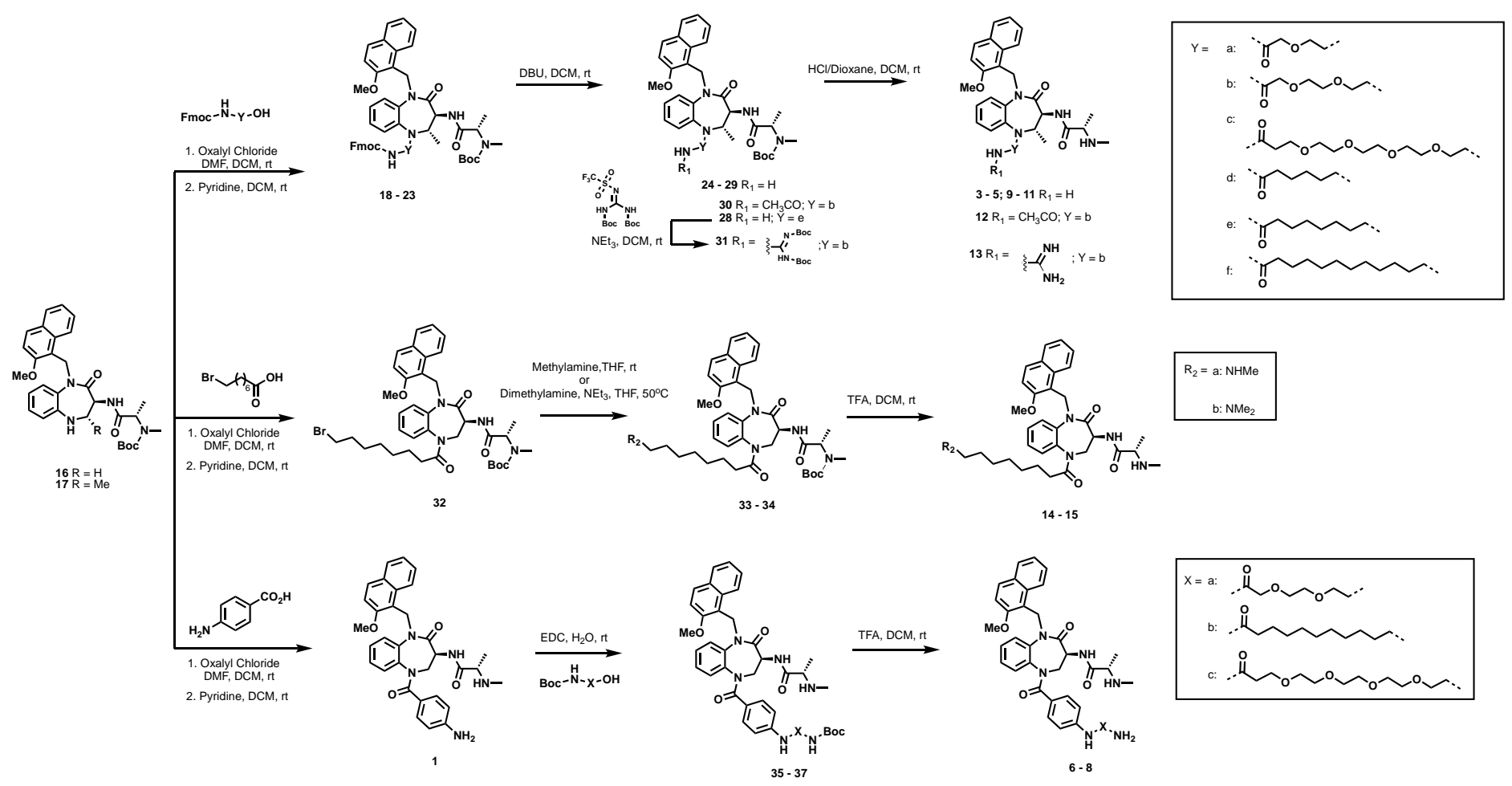

Scheme S1. Synthesis of amine-tagged BIR2 binders bearing varying linker lengths

\subsection{General synthetic procedures}

All reagents were purchased from commercial suppliers and used without further purification. Flash chromatography was performed using an ISCO CombiFlash RF with normal-phase silica gel cartridges. NMR spectra were recorded on Bruker spectrometers. Analytical LCMS data were collected on a Shimadzu LCMS and a ThermoScientific Q-Exactive Orbitrap. The purity of final compounds were determined to be $>95 \%$ by HPLC analysis on a Shimadzu LC-20AD monitored at $280 \mathrm{~nm}$.

\subsection{Experimental}

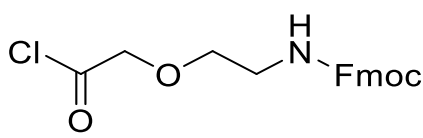

Step 1: (9H-Fluoren-9-yl)methyl (2-(2-chloro-2-oxoethoxy)ethyl)carbamate

Under nitrogen, to a solution of 2-(2-((( $9 \mathrm{H}$-fluoren-9-yl)methoxy)carbonyl)amino)ethoxy)acetic acid (562 mg, $1.65 \mathrm{mmol})$ in dichloromethane $(5 \mathrm{~mL})$ was added oxalic dichloride $(0.9 \mathrm{~mL}, 8.58 \mathrm{mmol})$ and $\mathrm{N}, \mathrm{N}$ dimethylformamide $(0.05 \mathrm{~mL}, 0.646 \mathrm{mmol})$ at $0{ }^{\circ} \mathrm{C}$. The resulting solution was stirred for $60 \mathrm{~min}$ at room temperature and used directly for next operation. 
<smiles>COc1ccc2ccccc2c1CN1C(=O)[C@H](NC(=O)[C@H](C)N(C)C(=O)OC(C)(C)C)[C@H](C)N(C(=O)COCCNC(C)C)c2ccccc21</smiles>

Step 2: tert-Butyl ((S)-1-(((2S,3S)-1-(2-(2-((((9H-fluoren-9-yl)methoxy)carbonyl)amino)ethoxy)acetyl)-5-((2methoxynaphthalen-1-yl)methyl)-2-methyl-4-oxo-2,3,4,5-tetrahydro-1H-benzo[b][1,4]diazepin-3-yl)amino)-1oxopropan-2-yl)(methyl)carbamate (18)

Under nitrogen, to a mixture of tert-butyl ((S)-1-(((3S,4S)-1-((2-methoxynaphthalen-1-yl)methyl)-4-methyl-2oxo-2,3,4,5-tetrahydro-1H-benzo[b][1,4]diazepin-3-yl)amino)-1-oxopropan-2-yl)(methyl)carbamate (17) (300 $\mathrm{mg}, 0.549 \mathrm{mmol})$ and pyridine $(217 \mathrm{mg}, 2.74 \mathrm{mmol})$ in dichloromethane $(5 \mathrm{~mL})$ was added a solution of $(9 \mathrm{H}$ fluoren-9-yl)methyl (2-(2-chloro-2-oxoethoxy)ethyl)carbamate (previous operation) in DCM (5 mL) dropwise at $0^{\circ} \mathrm{C}$. The reaction was then warmed to room temperature and stirred additional $3 \mathrm{~h}$. The reaction was quenched with water, extracted with ethyl acetate. The combined organic layers were dried over anhydrous sodium sulfate and concentrated under vacuum. The residue was purified by silica gel column eluting with methanol/ dichloromethane (0-15\%) to afford the title compound $300 \mathrm{mg}(63 \%)$ as a white solid. LC-MS: (ESI, $\mathrm{m} / \mathrm{z}):[\mathrm{M}+\mathrm{H}]^{+}$ $=870$<smiles>COc1ccc2ccccc2c1CN1C(=O)[C@H](NC(=O)[C@H](C)N(C)C(=O)OC(C)(C)C)[C@H](C)N(C(=O)COCCN)c2ccccc21</smiles>

Step 3: tert-Butyl ((S)-1-(((2S,3S)-1-(2-(2-aminoethoxy)acetyl)-5-((2-methoxynaphthalen-1-yl)methyl)-2-methyl4-oxo-2,3,4,5-tetrahydro-1H-benzo[b][1,4]diazepin-3-yl)amino)-1-oxopropan-2-yl)(methyl)carbamate (24)

Under nitrogen, to a solution of $18(100 \mathrm{mg}, 0.115 \mathrm{mmol})$ and DBU (40 mg, $0.263 \mathrm{mmol})$ in dichloromethane (5 $\mathrm{mL}$ ) was stirred for 1 hour at room temperature. The solvent was removed under vacuum and the residual was purified by silica gel column eluting with EtOAc/petroleum ether (0-30\%) to afford the title compound $50 \mathrm{mg}$ (67\%) as a white solid. LC-MS: $(E S I, m / z):[M+H]^{+}=648$ 
<smiles>CN[C@@H](C)C(=O)N[C@H]1C(=O)N(Cc2c(OC)ccc3ccccc23)c2ccccc2N(C(=O)COCCN)[C@@H]1C</smiles>

Step 4: (S)-N-((2S,3S)-1-(2-(2-Aminoethoxy)acetyl)-5-((2-methoxynaphthalen-1-yl)methyl)-2-methyl-4-oxo2,3,4,5-tetrahydro-1H-benzo[b][1,4]diazepin-3-yl)-2-(methylamino)propenamide (3)

Under nitrogen, to a solution of $\mathbf{2 4}(50 \mathrm{mg}, 0.077 \mathrm{mmol})$ in dichloromethane $(5 \mathrm{~mL})$ was added $\mathrm{HCl} /$ dioxane $(4 \mathrm{M}$, $0.5 \mathrm{~mL}$ ). The resulting solution was stirred for 1 hour at room temperature. The $\mathrm{pH}$ was adjusted to $\sim 8$ with ammonium hydroxide solution (1 mol/L). Concentrated under vacuum. The residue was purified by reverse phase column $\left(\mathrm{ACN} / \mathrm{H}_{2} \mathrm{O} / \mathrm{NH}_{4} \mathrm{HCO}_{3}(0.5 \%)=0 \sim 100 \%\right)$ to afford the title compound $4.1 \mathrm{mg}(9 \%)$ as a white solid. LC-MS: (ESI, m/z): $[\mathrm{M}+\mathrm{H}]^{+}=548 ;{ }^{1} \mathrm{H}$ NMR $\left(300 \mathrm{MHz}, \mathrm{DMSO}-\mathrm{d}_{6}\right) \delta 8.48(\mathrm{~d}, J=9.1 \mathrm{~Hz}, 1 \mathrm{H}), 8.14-7.98(\mathrm{~m}, 1 \mathrm{H}), 7.97$ $-7.73(\mathrm{~m}, 3 \mathrm{H}), 7.49(\mathrm{td}, J=7.7,1.6 \mathrm{~Hz}, 1 \mathrm{H}), 7.42-7.25(\mathrm{~m}, 3 \mathrm{H}), 7.21(\mathrm{td}, J=7.6,1.3 \mathrm{~Hz}, 1 \mathrm{H}), 7.16-7.09(\mathrm{~m}, 1 \mathrm{H})$, $5.92(\mathrm{~d}, J=14.7 \mathrm{~Hz}, 1 \mathrm{H}), 5.32(\mathrm{~d}, J=14.6 \mathrm{~Hz}, 1 \mathrm{H}), 4.75(\mathrm{dq}, J=12.4,6.2 \mathrm{~Hz}, 1 \mathrm{H}), 4.11(\mathrm{dd}, J=11.7,9.0 \mathrm{~Hz}, 1 \mathrm{H})$, $3.81(\mathrm{~d}, J=2.1 \mathrm{~Hz}, 3 \mathrm{H}), 2.99(\mathrm{q}, J=6.8 \mathrm{~Hz}, 1 \mathrm{H}), 2.74-2.62(\mathrm{~m}, 1 \mathrm{H}), 2.62-2.55(\mathrm{~m}, 1 \mathrm{H}), 2.51(\mathrm{~s}, 2 \mathrm{H}), 2.37(\mathrm{t}, J=$ $5.7 \mathrm{~Hz}, 2 \mathrm{H}), 2.21(\mathrm{~s}, 3 \mathrm{H}), 1.32(\mathrm{~d}, J=13.5 \mathrm{~Hz}, 1 \mathrm{H}), 1.10(\mathrm{~d}, J=6.8 \mathrm{~Hz}, 3 \mathrm{H}), 0.90(\mathrm{~d}, J=6.2 \mathrm{~Hz}, 3 \mathrm{H})$.<smiles>O=C(Cl)COCCOCCNC(F)F</smiles>

Step 1: (9H-Fluoren-9-yl)methyl (2-(2-(2-chloro-2-oxoethoxy)ethoxy)ethyl)carbamate

Under nitrogen, to a solution of 1-(9H-fluoren-9-yl)-3-oxo-2,7,10-trioxa-4-azadodecan-12-oic acid (560 mg, 1.45 mmol) in dichloromethane $(4 \mathrm{~mL})$ was added $\mathrm{N}, \mathrm{N}$-dimethylformamide $(0.05 \mathrm{~mL}, 0.646 \mathrm{mmol})$ and oxalyl dichloride $(0.9 \mathrm{~mL}, 8.71 \mathrm{mmol})$ dropwise. The resulting solution was stirred for $60 \mathrm{~min}$ at room temperature and used directly for next operation.

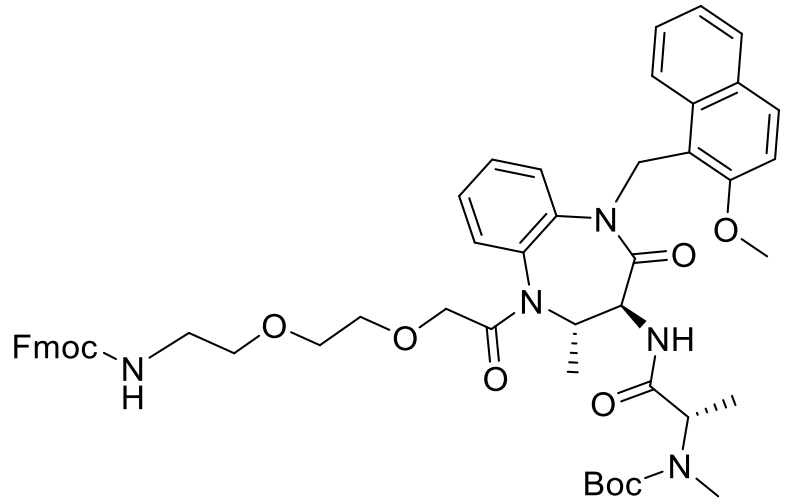

Step 2: tert-Butyl ((S)-1-(((2S,3S)-1-(1-(9H-fluoren-9-yl)-3-oxo-2,7,10-trioxa-4-azadodecan-12-oyl)-5-((2methoxynaphthalen-1-yl)methyl)-2-methyl-4-oxo-2,3,4,5-tetrahydro-1H-benzo[b][1,4]diazepin-3-yl)amino)-1oxopropan-2-yl)(methyl)carbamate (19)

Under nitrogen, to a solution of 17 (217 mg, $2.74 \mathrm{mmol})$ in DCM, was added a solution of ( $9 H$-fluoren-9-yl)methyl (2-(2-(2-chloro-2-oxoethoxy)ethoxy)ethyl)carbamate (from previous operation) in dichloromethane dropwise at 
$0^{\circ} \mathrm{C}$. The resulting solution was stirred for $3 \mathrm{~h}$ at room temperature. The reaction was quenched with water, extracted with of ethyl acetate. The combined organic layers were dried over anhydrous sodium sulfate and concentrated under vacuum. The residue was purified by silica gel column eluting with ethyl acetate/petroleum ether (0 20\%) to afford the title compound $300 \mathrm{mg}(60 \%)$ as a white solid. LC-MS: $(\mathrm{ESI}, \mathrm{m} / \mathrm{z}):[\mathrm{M}+\mathrm{H}]^{+}=914$<smiles>COc1ccc2ccccc2c1CN1C(=O)[C@H](NC(=O)[C@H](C)N(C)C(=O)OC(C)(C)C)[C@H](C)N(C(=O)COCCOCCN)c2ccccc21</smiles>

Step 3: tert-Butyl ((S)-1-(((2S,3S)-1-(2-(2-(2-aminoethoxy)ethoxy)acetyl)-5-((2-methoxynaphthalen-1yl)methyl)-2-methyl-4-oxo-2,3,4,5-tetrahydro-1H-benzo[b][1,4]diazepin-3-yl)amino)-1-oxopropan-2$\mathrm{yl}$ )(methyl)carbamate (25)

Under nitrogen, to a solution of $19(270 \mathrm{mg}, 0.295 \mathrm{mmol})$ in dichloromethane $(5 \mathrm{~mL})$ was added DBU (141 mg, $0.926 \mathrm{mmol}$ ). The resulting solution was stirred for $30 \mathrm{~min}$ at room temperature. The resulting mixture was concentrated under vacuum. The residue was purified by silica gel column eluting with methanol / dichloromethane $(0 \sim 20 \%)$ to afford the titled compound $150 \mathrm{mg}(73 \%)$ as a yellow solid. LC-MS: (ESI, m/z): $[\mathrm{M}+\mathrm{H}]^{+}=692$

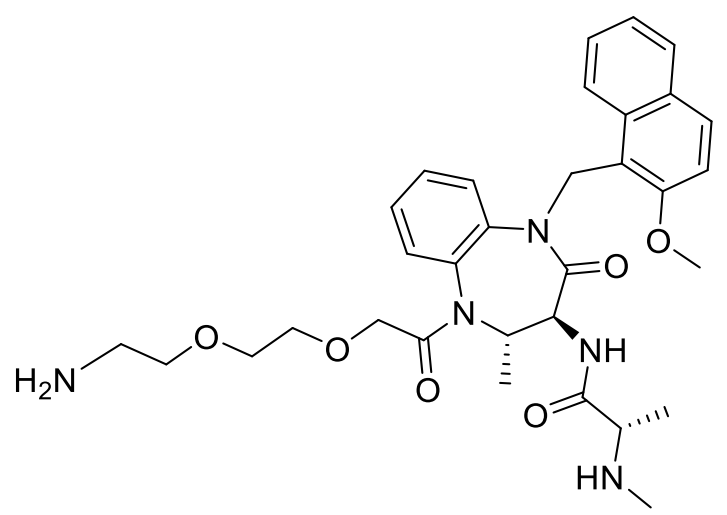

Step 4: tert-Butyl $(S)-N-((2 S, 3 S)-1-(2-(2-(2-a m i n o e t h o x y)$ ethoxy)acetyl)-5-((2-methoxynaphthalen-1-yl)methyl)2-methyl-4-oxo-2,3,4,5-tetrahydro-1H-benzo[b][1,4]diazepin-3-yl)-2-(methylamino)propenamide (4)

To a solution of 25 in dichloromethane $(1 \mathrm{~mL})$ was added $\mathrm{HCl}(\mathrm{g})$ in dioxane $(1 \mathrm{ml}, 4 \mathrm{M})$. The resulting solution was stirred for $60 \mathrm{~min}$ at room temperature. The resulting mixture was concentrated under vacuum. The crude product was purified by Prep-HPLC with the following conditions (Column, Xbridge Phenyl OBD Column,, 5um,19*150mm; mobile phase, Waters(10MMOL/L NH4HCO3) and ACN (25.0\% to 60.0\% in 8 min); Detector, UV 220nm) to afford the title compound $8 \mathrm{mg}(47 \%)$ as a white solid. LC-MS: (ESI, $\mathrm{m} / \mathrm{z}):[\mathrm{M}+\mathrm{H}]^{+}=592 ;{ }^{1} \mathrm{H} \mathrm{NMR}$ $\left(300 \mathrm{MHz}, \mathrm{DMSO}-d_{6}\right): \delta(\mathrm{ppm}) 8.50(\mathrm{~d}, J=9.0 \mathrm{~Hz}, 1 \mathrm{H}), 8.05(\mathrm{~d}, J=8.6 \mathrm{~Hz}, 1 \mathrm{H}), 7.93-7.73(\mathrm{~m}, 3 \mathrm{H}), 7.51(\mathrm{t}, J=7.3$ $\mathrm{Hz}, 1 \mathrm{H}$ ), 7.34 (qd, $J=9.2,8.0,4.4 \mathrm{~Hz}, 3 \mathrm{H}), 7.23(\mathrm{td}, J=8.0,2.7 \mathrm{~Hz}, 1 \mathrm{H}), 7.14(\mathrm{~d}, J=7.8 \mathrm{~Hz}, 1 \mathrm{H}), 5.94(\mathrm{~d}, J=14.6$ $\mathrm{Hz}, 1 \mathrm{H}), 5.34(\mathrm{~d}, J=14.7 \mathrm{~Hz}, 1 \mathrm{H}), 4.78(\mathrm{dd}, J=11.8,6.2 \mathrm{~Hz}, 1 \mathrm{H}), 4.13(\mathrm{dd}, J=11.7,9.0 \mathrm{~Hz}, 1 \mathrm{H}), 3.84(\mathrm{~s}, 3 \mathrm{H}), 3.25$ $(\mathrm{t}, J=5.6 \mathrm{~Hz}, 6 \mathrm{H}), 3.00(\mathrm{dd}, J=8.3,5.6 \mathrm{~Hz}, 2 \mathrm{H}), 2.86-2.83(\mathrm{~m}, 1 \mathrm{H}), 2.79-2.66(\mathrm{~m}, 2 \mathrm{H}), 2.66-2.55(\mathrm{~m}, 2 \mathrm{H}), 2.23(\mathrm{~s}$, $3 \mathrm{H}), 1.35(\mathrm{dd}, J=13.6,8.2 \mathrm{~Hz}, 1 \mathrm{H}), 1.12(\mathrm{~d}, J=6.8 \mathrm{~Hz}, 3 \mathrm{H}), 0.92(\mathrm{~d}, J=6.2 \mathrm{~Hz}, 3 \mathrm{H})$. 
<smiles>O=C(Cl)CCOCCOCCOCCOCCNC(F)F</smiles>

Step 1: (9H-Fluoren-9-yl)methyl (15-chloro-15-oxo-3,6,9,12-tetraoxapentadecyl)carbamate

Under nitrogen, to the solution of 1-(9H-fluoren-9-yl)-3-oxo-2,7,10,13,16-pentaoxa-4-azanonadecan-19-oic acid $(670 \mathrm{mg}, 1.37 \mathrm{mmol})$ in dichloromethane $(5 \mathrm{~mL}, 78.7 \mathrm{mmol})$ was added $\mathrm{N}, \mathrm{N}$-dimethylformamide $(0.05 \mathrm{~mL}, 0.646$ $\mathrm{mmol}$ ) and oxalic dichloride $(0.75 \mathrm{~mL}, 1.77 \mathrm{mmol})$ dropwise at $0{ }^{\circ} \mathrm{C}$. The resulting solution was stirred for $1 \mathrm{~h}$ at room temperature and used directly for next operation.

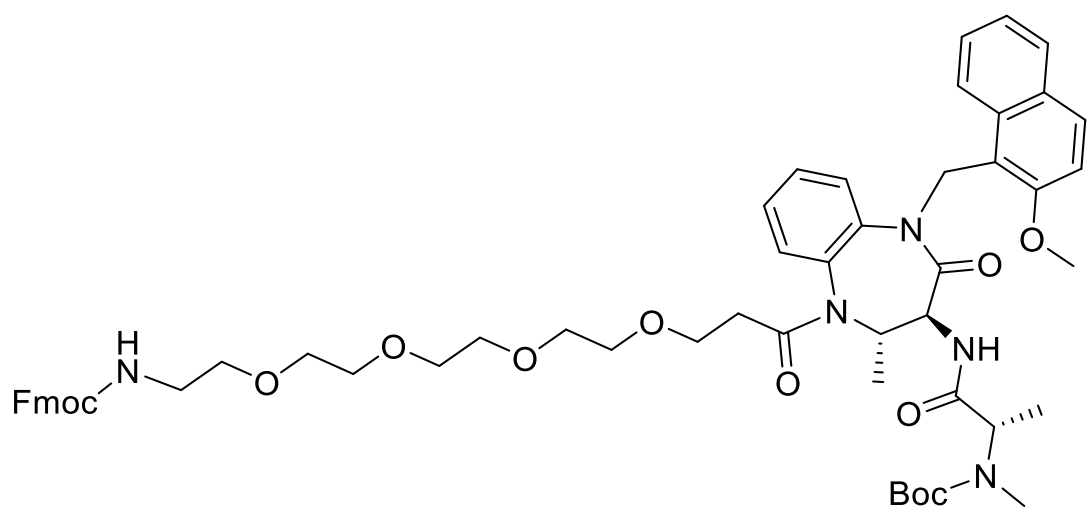

Step 2: tert-Butyl ((S)-1-(((2S,3S)-1-(1-(9H-fluoren-9-yl)-3-oxo-2,7,10,13,16-pentaoxa-4-azanonadecan-19-oyl)5-((2-methoxynaphthalen-1-yl)methyl)-2-methyl-4-oxo-2,3,4,5-tetrahydro-1H-benzo[b][1,4]diazepin-3yl)amino)-1-oxopropan-2-yl)(methyl)carbamate (20)

Under nitrogen, to solution of $17(250 \mathrm{mg}, 0.457 \mathrm{mmol})$ in dichloromethane $(3 \mathrm{~mL})$ was added pyridine (183 $\mathrm{mg}$, $2.31 \mathrm{mmol}$ ) and (9H-fluoren-9-yl)methyl (15-chloro-15-oxo-3,6,9,12-tetraoxapentadecyl)carbamate (crude solution) dropwise at $0{ }^{\circ} \mathrm{C}$. The reaction was stirred at room temperature for $2 \mathrm{~h}$. The reaction solution was quenched with water, extracted with dichloromethane. The combined organic layers were dried over anhydrous sodium sulfate and concentrated under vacuum. The residue was purified by flash chromatography on silica gel eluting with ethyl acetate/petroleum ether (0-100\%) to afford the title compound $410 \mathrm{mg}(88 \%)$ as a white solid. LC-MS: $(E S I, m / z):[M+H]^{+}=1016$

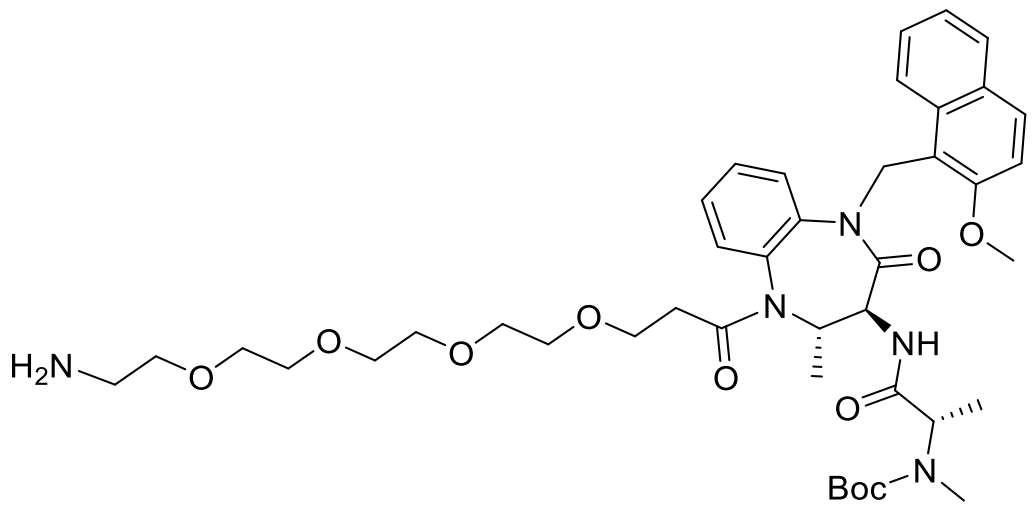

Step 3: tert-Butyl ((S)-1-(((2S,3S)-1-(1-amino-3,6,9,12-tetraoxapentadecan-15-oyl)-5-((2-methoxynaphthalen-1yl)methyl)-2-methyl-4-oxo-2,3,4,5-tetrahydro-1H-benzo[b][1,4]diazepin-3-yl)amino)-1-oxopropan-2yl)(methyl)carbamate (26)

To a solution of 20 (410 mg, $0.403 \mathrm{mmol})$ in dichloromethane $(4 \mathrm{~mL})$ was added DBU (184 mg, $1.21 \mathrm{mmol})$. The resulting solution was stirred for $30 \mathrm{~min}$ at room temperature and concentrated under vacuum. The residue 
was purified by silica gel column eluting with dichloromethane/methanol (0-20\%) to afford the title compound $220 \mathrm{mg}(69 \%)$ as a white solid. LC-MS (ESI, $\mathrm{m} / \mathrm{z}):[\mathrm{M}+\mathrm{H}]^{+}=794$

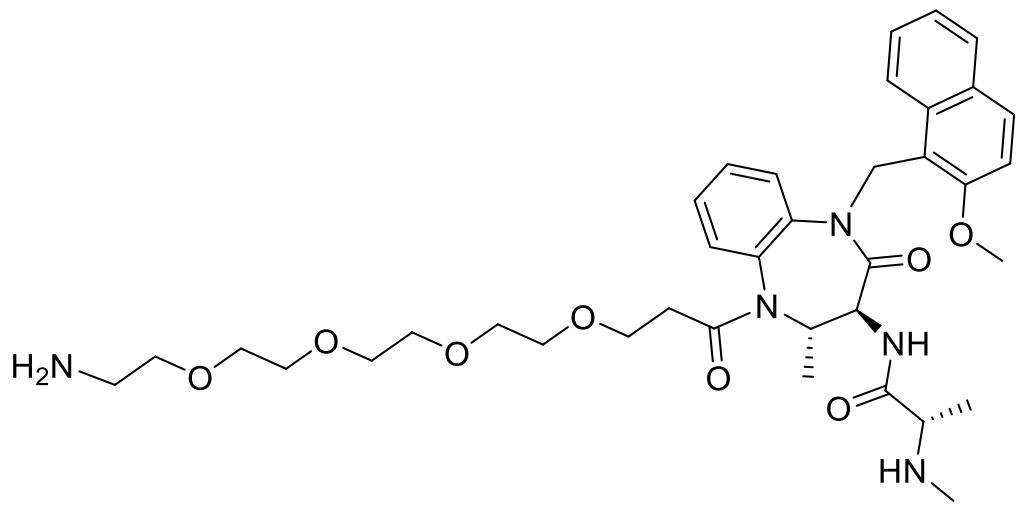

Step 4: (S)-N-((2S,3S)-1-(1-Amino-3,6,9,12-tetraoxapentadecan-15-oyl)-5-((2-methoxynaphthalen-1-yl)methyl)2-methyl-4-oxo-2,3,4,5-tetrahydro-1H-benzo[b][1,4]diazepin-3-yl)-2-(methylamino)propenamide (5)

To a solution 26 (40 mg, $0.050 \mathrm{mmol})$ in dichloromethane $(2 \mathrm{~mL}, 31.460 \mathrm{mmol})$ was added HCl/dioxane $(1 \mathrm{~mL}$, $4 \mathrm{M}$ ). The resulting solution was stirred for $30 \mathrm{~min}$ at room temperature and concentrated under vacuum. The crude product was purified by Prep-HPLC with the following conditions (Column, XBridge Shield RP18 OBD Column, 19*150mm 5um 13nm; mobile phase, Water with $10 \mathrm{mmol} \mathrm{NH}_{4} \mathrm{HCO}_{3}$ and $\mathrm{MeCN}(20.0 \% \mathrm{MeCN}$ up to $60.0 \%$ in $9 \mathrm{~min}) ;$ Detector, UV 254nm) to afford the title compound $13 \mathrm{mg}(43 \%)$ as a white solid. LC-MS (ESI, $\mathrm{m} / \mathrm{z}):[\mathrm{M}+\mathrm{H}]^{+}=694 ;{ }^{1} \mathrm{H} \mathrm{NMR}\left(400 \mathrm{MHz}, \mathrm{DMSO}-\mathrm{d}_{6}\right) \delta 8.48(\mathrm{~d}, J=9.2 \mathrm{~Hz}, 1 \mathrm{H}), 8.03(\mathrm{t}, J=5.6 \mathrm{~Hz}, 1 \mathrm{H}), 7.87(\mathrm{~d}, J=$ $8.0 \mathrm{~Hz}, 1 \mathrm{H}), 7.83-7.76(\mathrm{~m}, 2 \mathrm{H}), 7.52(\mathrm{t}, J=7.6 \mathrm{~Hz}, 1 \mathrm{H}), 7.39-7.31(\mathrm{~m}, 2 \mathrm{H}), 7.25(\mathrm{dd}, J=9.2,18.0 \mathrm{~Hz}, 2 \mathrm{H}), 7.14(\mathrm{~d}$, $J=7.6 \mathrm{~Hz}, 1 \mathrm{H}), 5.94(\mathrm{~d}, J=14.8 \mathrm{~Hz}, 1 \mathrm{H}), 5.33(\mathrm{~d}, J=14.8 \mathrm{~Hz}, 1 \mathrm{H}), 4.77(\mathrm{dq}, J=6.0,12.0 \mathrm{~Hz}, 1 \mathrm{H}), 4.11(\mathrm{dd}, J=9.2$, $11.6 \mathrm{~Hz}, 1 \mathrm{H}), 3.83(\mathrm{~s}, 3 \mathrm{H}), 3.57-3.45(\mathrm{~m}, 8 \mathrm{H}), 3.30-3.25(\mathrm{~m}, 7 \mathrm{H}), 3.23-3.15(\mathrm{~m}, 2 \mathrm{H}), 3.08-2.97(\mathrm{~m}, 3 \mathrm{H}), 2.63(\mathrm{t}, J=$ $5.6 \mathrm{~Hz}, 1 \mathrm{H}), 2.40(\mathrm{td}, J=4.6,8.8, \mathrm{~Hz}, 1 \mathrm{H}), 2.22(\mathrm{~s}, 3 \mathrm{H}), 1.27(\mathrm{dt}, J=7.8,15.7 \mathrm{~Hz}, 1 \mathrm{H}), 1.11(\mathrm{~d}, J=6.8 \mathrm{~Hz}, 3 \mathrm{H}), 0.88$ $(\mathrm{d}, J=6.8 \mathrm{~Hz}, 3 \mathrm{H}),-0.41$ (ddd, $J=4.6,8.0,15.9 \mathrm{~Hz}, 1 \mathrm{H})$.<smiles>O=C(Cl)CCCCCCNC(F)F</smiles>

Step 1: (9H-Fluoren-9-yl)methyl (7-chloro-7-oxoheptyl)carbamate (28)

Under nitrogen, to a solution of 7-((( $9 \mathrm{H}$-fluoren-9-yl)methoxy)carbonyl)amino)heptanoic acid (848 $\mathrm{mg}, 2.31$ $\mathrm{mmol}$ ) in dichloromethane $(5 \mathrm{~mL})$ was added oxalyl dichloride $(320 \mathrm{mg}, 2.52 \mathrm{mmol}$ ) and DMF (3 mg, $0.041 \mathrm{mmol})$ at room temperature. The resulting solution was stirred at room temperature for $10 \mathrm{~min}$. The reaction solution was used for next operation.<smiles>COc1ccc2ccccc2c1CN1C(=O)[C@H](NC(=O)[C@H](C)N(C)C(=O)OC(C)(C)C)[C@@H](C)N(C(=O)CCCCCCNC(=O)OC(F)(F)C(C)(C)C)c2ccccc21</smiles> 
Step 2: tert-Butyl $\quad((S)-1-(((2 S, 3 S)-1-(7-((((9 H-F l u o r e n-9-y l) m e t h o x y)$ carbonyl)amino)heptanoyl)-5-((2methoxynaphthalen-1-yl)methyl)-2-methyl-4-oxo-2,3,4,5-tetrahydro-1H-benzo[b][1,4]diazepin-3-yl)amino)-1oxopropan-2-yl)(methyl)carbamate (21)

Under nitrogen, to a solution of $17(400 \mathrm{mg}, 0.732 \mathrm{mmol})$ in dichloromethane $(10 \mathrm{~mL})$ was added pyridine (340 $\mathrm{mg}, 4.30 \mathrm{mmol}$ ) and a freshly prepared solution of $(9 \mathrm{H}$-fluoren-9-yl)methyl (7-chloro-7-oxoheptyl)carbamate (from previous step) dropwise at $0{ }^{\circ} \mathrm{C}$. The resulting solution was stirred at room temperature for $3 \mathrm{~h}$. The reaction system was quenched with water, extracted with dichloromethane. The combined organic layers were washed with brine, dried over anhydrous sodium sulfate and concentrated under vacuum. The residue was purified by silica gel column eluting with ethyl acetate/petroleum ether (0 50\%) to afford the title compound $400 \mathrm{mg}(61 \%)$ as a white solid. LC-MS: (ESI, m/z): $[\mathrm{M}+\mathrm{H}]^{+}=896$

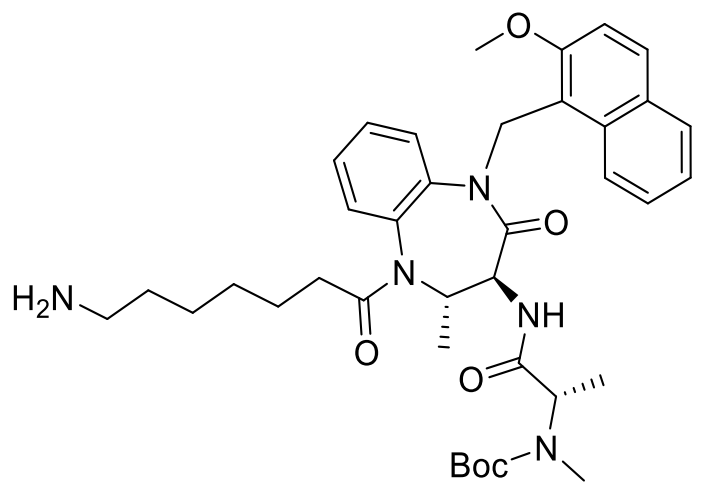

Step 3: tert-Butyl ((S)-1-(((2S,3S)-1-(7-Aminoheptanoyl)-5-((2-methoxynaphthalen-1-yl)methyl)-2-methyl-4-oxo2,3,4,5-tetrahydro-1H-benzo[b][1,4]diazepin-3-yl)amino)-1-oxopropan-2-yl)(methyl)carbamate (27)

Under nitrogen, to a solution of $21(380 \mathrm{mg}, 0.424 \mathrm{mmol})$ in dichloromethane $(5 \mathrm{~mL})$ was added DBU (200 mg, $1.31 \mathrm{mmol}$ ) at room temperature. The resulting solution was stirred for 2 hours at room temperature. The solvent was removed under vacuum and the residue was purified by silica gel column eluting with ethyl acetate/petroleum ether (0 70\%) to afford the title compound $195 \mathrm{mg}(68 \%)$ as an off-white solid. LC-MS: (ESI, $\mathrm{m} / \mathrm{z}):[\mathrm{M}+\mathrm{H}]^{+}=674$

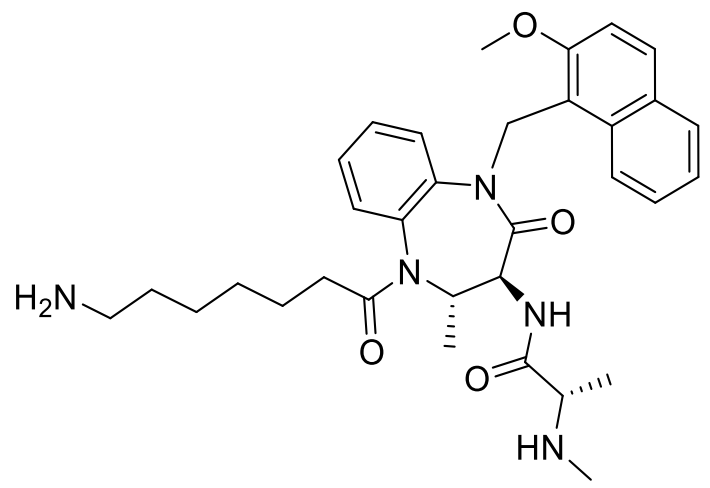

Step 4: (S)-N-((2S,3S)-1-(7-Aminoheptanoyl)-5-((2-methoxynaphthalen-1-yl)methyl)-2-methyl-4-oxo-2,3,4,5tetrahydro-1H-benzo[b][1,4]diazepin-3-yl)-2-(methylamino)propenamide (9)

To a solution of $\mathbf{2 7}(5 \mathrm{~mL})$ was added $\mathrm{HCl}$ /dioxane $(4 \mathrm{M}, 0.5 \mathrm{~mL})$ at room temperature. The resulting solution was stirred for $1 \mathrm{~h}$ at room temperature and concentrated under vacuum. The residual was purified by reverse phase column eluting with $\mathrm{CH} 3 \mathrm{CN} / \mathrm{H} 2 \mathrm{O}(0.5 \% \mathrm{NH} 4 \mathrm{HCO})$ to afford $6.7 \mathrm{mg}(16 \%)$ of the title compound as a white solid. LC-MS: (ESI, m/z): $[\mathrm{M}+\mathrm{H}]^{+}=574 ;{ }^{1} \mathrm{H} N M R\left(400 \mathrm{MHz}, \mathrm{DMSO}-\mathrm{d}_{6}\right) \delta 8.48(\mathrm{~d}, J=9.1 \mathrm{~Hz}, 1 \mathrm{H}), 8.15-8.01(\mathrm{~m}, 1 \mathrm{H}), 7.90$ $(\mathrm{d}, J=8.2 \mathrm{~Hz}, 1 \mathrm{H}), 7.79(\mathrm{~d}, J=9.8 \mathrm{~Hz}, 2 \mathrm{H}), 7.52(\mathrm{t}, J=7.8 \mathrm{~Hz}, 1 \mathrm{H}), 7.43-7.17(\mathrm{~m}, 4 \mathrm{H}), 7.06(\mathrm{~d}, J=7.9 \mathrm{~Hz}, 1 \mathrm{H}), 5.94$ $(\mathrm{d}, J=14.8 \mathrm{~Hz}, 1 \mathrm{H}), 5.33(\mathrm{~d}, J=14.7 \mathrm{~Hz}, 1 \mathrm{H}), 4.77(\mathrm{dq}, J=12.6,6.3 \mathrm{~Hz}, 1 \mathrm{H}), 4.10(\mathrm{dd}, J=11.6,9.0 \mathrm{~Hz}, 1 \mathrm{H}), 3.83(\mathrm{~s}$, $3 \mathrm{H}), 3.00(\mathrm{q}, J=6.8 \mathrm{~Hz}, 1 \mathrm{H}), 2.85(\mathrm{q}, J=6.6 \mathrm{~Hz}, 1 \mathrm{H}), 2.46(\mathrm{~d}, J=7.0 \mathrm{~Hz}, 2 \mathrm{H}), 2.21(\mathrm{~s}, 3 \mathrm{H}), 1.21(\mathrm{~h}, J=7.8,7.3 \mathrm{~Hz}$, 
$2 \mathrm{H}), 1.11(\mathrm{~d}, J=6.8 \mathrm{~Hz}, 3 \mathrm{H}), 0.91(\mathrm{dd}, J=22.8,7.1 \mathrm{~Hz}, 8 \mathrm{H}), 0.58(\mathrm{tt}, J=12.1,6.8 \mathrm{~Hz}, 1 \mathrm{H}), 0.46(\mathrm{q}, J=11.3,9.1 \mathrm{~Hz}$, $1 \mathrm{H}), 0.29(\mathrm{tt}, J=16.1,7.3 \mathrm{~Hz}, 1 \mathrm{H}),-0.59(\mathrm{td}, J=12.6,9.6,4.2 \mathrm{~Hz}, 1 \mathrm{H})$.<smiles>O=C(Cl)CCCCCCCNCPC(=O)O</smiles>

Step 1: (9H-Fluoren-9-yl)methyl (8-chloro-8-oxooctyl)carbamate

Under nitrogen, to the solution of $8-((((9 \mathrm{H}-$ fluoren-9-yl)methoxy)carbonyl)amino)octanoic acid (522 mg, 1.37 $\mathrm{mmol})$ in dichloromethane $(5 \mathrm{~mL})$ was added oxalyl dichloride $(0.75 \mathrm{~mL}, 1.536 \mathrm{mmol})$ and $\mathrm{N}, \mathrm{N}-$ dimethylformamide $(0.05 \mathrm{~mL}, 0.646 \mathrm{mmol})$ dropwise at $0{ }^{\circ} \mathrm{C}$. The resulting solution was stirred for $1 \mathrm{~h}$ at room temperature and used directly for next operation.

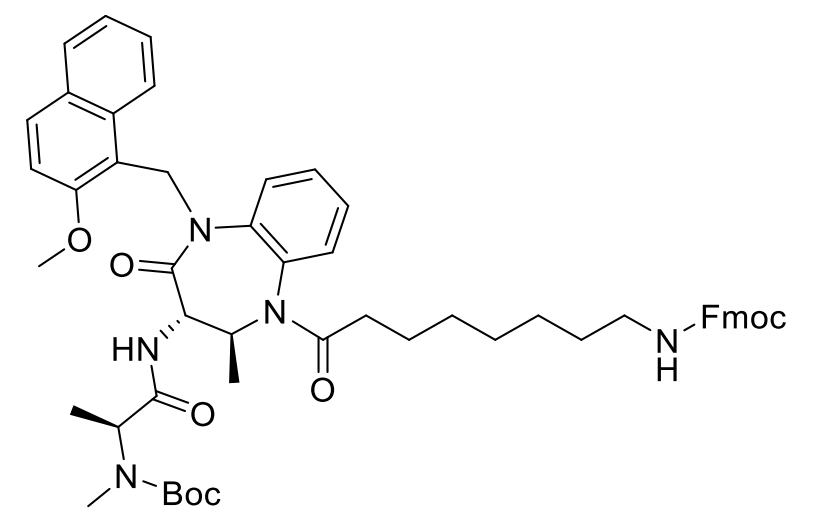

Step 2: tert-Butyl $\quad((S)-1-(((2 S, 3 S)-1-(8-((((9 H-$ fluoren-9-yl)methoxy)carbonyl)amino)octanoyl)-5-((2methoxynaphthalen-1-yl)methyl)-2-methyl-4-oxo-2,3,4,5-tetrahydro-1H-benzo[b][1,4]diazepin-3-yl)amino)-1oxopropan-2-yl)(methyl)carbamate (22)

Under nitrogen, to a solution of $17(250 \mathrm{mg}, 0.457 \mathrm{mmol})$ in dichloromethane $(3 \mathrm{~mL})$ was added a solution of (9H-fluoren-9-yl)methyl (8-chloro-8-oxooctyl)carbamate in dichloromethane from previous operation and pyridine $(183 \mathrm{mg}, 2.31 \mathrm{mmol})$ at $0^{\circ} \mathrm{C}$. The reaction solution was stirred at room temperature for 2 hours. The reaction was then quenched with water, extracted with dichloromethane. The combined organic layers were dried over anhydrous sodium sulfate and concentrated under vacuum. The residue was purified by silica gel column eluting with ethyl acetate/petroleum ether (0-70\%) to afford the title compound $315 \mathrm{mg}(76 \%)$ as a white solid. LC-MS (ESI, m/z): $[\mathrm{M}+\mathrm{H}]^{+}=910$

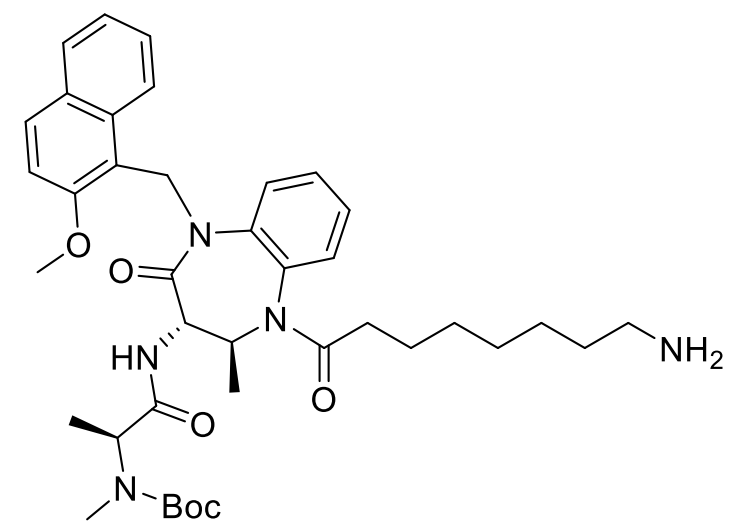

Step 3: tert-Butyl ((S)-1-(((2S,3S)-1-(8-aminooctanoyl)-5-((2-methoxynaphthalen-1-yl)methyl)-2-methyl-4-oxo2,3,4,5-tetrahydro-1H-benzo[b][1,4]diazepin-3-yl)amino)-1-oxopropan-2-yl)(methyl)carbamate (28) 
Under nitrogen, to the solution of $22(315 \mathrm{mg}, 0.346 \mathrm{mmol})$ in dichloromethane $(5 \mathrm{~mL})$ was added DBU (158 mg, $1.04 \mathrm{mmol}$ ). The resulting solution was stirred for $30 \mathrm{~min}$ at room temperature. The resulting mixture was concentrated under vacuum. The residue was purified by silica gel column eluting with dichloromethane/methanol (0-20\%) to afford the title compound $190 \mathrm{mg}(80 \%)$ o as a white solid. LC-MS (ESI, $\mathrm{m} / \mathrm{z}):[\mathrm{M}+\mathrm{H}]^{+}=688$

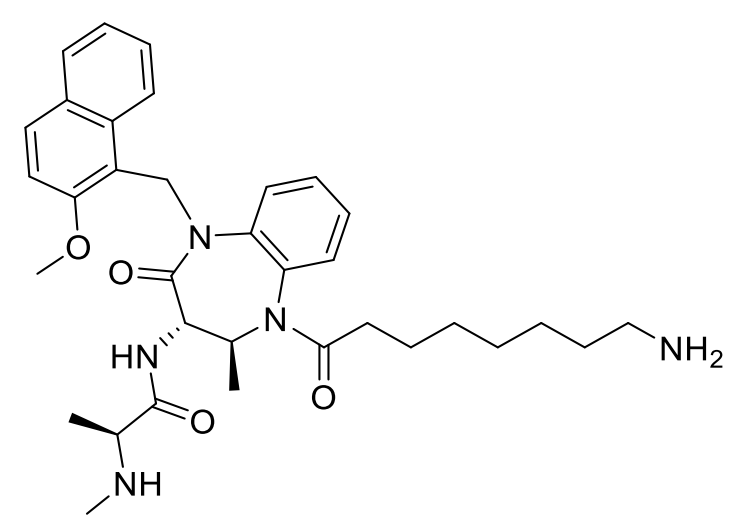

Step 4: (S)-N-((2S,3S)-1-(8-Aminooctanoyl)-5-((2-methoxynaphthalen-1-yl)methyl)-2-methyl-4-oxo-2,3,4,5tetrahydro-1H-benzo[b][1,4]diazepin-3-yl)-2-(methylamino)propenamide (10)

To a solution of $\mathbf{2 8}(3 \mathrm{~mL})$ was added $\mathrm{HCl}$ /dioxane $(2 \mathrm{~mL}, 6 \mathrm{M})$. The resulting solution was stirred for $1 \mathrm{~h}$ at room temperature. The resulting mixture was concentrated under vacuum. The crude product was purified by PrepHPLC with the following conditions (Column, Gemini-NX C18 AXAI Packed, 21.2*150mm 5um; mobile phase, $\mathrm{H}_{2} \mathrm{O}\left(10 \mathrm{M} \mathrm{NH}_{4} \mathrm{HCO}_{3}\right)$ and $\mathrm{ACN}$ (14\% ACN to 48\% in $6 \mathrm{~min}$ ); Detector, UV 254/220nm) to afford the title compound $20 \mathrm{mg}(59 \%)$ as a white solid. LC-MS (ESI, m/z): $[\mathrm{M}+\mathrm{H}]^{+}=588 ;{ }^{1} \mathrm{H}$ NMR $\left(400 \mathrm{MHz}, \mathrm{DMSO}-d_{6}\right) \delta 8.48(\mathrm{~d}, J=9.2 \mathrm{~Hz}$, $1 \mathrm{H}), 8.05(\mathrm{dt}, J=6.6,3.4 \mathrm{~Hz}, 1 \mathrm{H}), 7.90(\mathrm{dd}, J=8.2,1.4 \mathrm{~Hz}, 1 \mathrm{H}), 7.80-7.74(\mathrm{~m}, 2 \mathrm{H}), 7.52(\mathrm{t}, J=7.6,1 \mathrm{H}), 7.35-$ $7.21(\mathrm{~m}, 4 \mathrm{H}), 7.06(\mathrm{dd}, J=7.8,1.4 \mathrm{~Hz}, 1 \mathrm{H}), 5.94(\mathrm{~d}, J=14.8 \mathrm{~Hz}, 1 \mathrm{H}), 5.33(\mathrm{~d}, J=14.8 \mathrm{~Hz}, 1 \mathrm{H}), 4.77(\mathrm{dt}, J=12.4$, $6.2 \mathrm{~Hz}, 1 \mathrm{H}$ ), $4.10(\mathrm{dd}, J=11.8,9.0 \mathrm{~Hz}, 1 \mathrm{H}), 3.83(\mathrm{~s}, 3 \mathrm{H}), 3.00(\mathrm{q}, J=6.8 \mathrm{~Hz}, 1 \mathrm{H}), 2.88(\mathrm{q}, J=6.8 \mathrm{~Hz}, 1 \mathrm{H}), 2.49-2.47$ $(\mathrm{m}, 2 \mathrm{H}), 2.22(\mathrm{~s}, 3 \mathrm{H}), 1.30-1.22(\mathrm{~m}, 2 \mathrm{H}), 1.14-1.03(\mathrm{~m}, 5 \mathrm{H}), 0.99-0.78(\mathrm{~m}, 7 \mathrm{H}), 0.62-0.41(\mathrm{~m}, 2 \mathrm{H}), 0.37-$ $0.25(\mathrm{~m}, 1 \mathrm{H}),-0.58$ (ddd, $J=15.8,11.0,4.8 \mathrm{~Hz}, 1 \mathrm{H}) ;{ }^{13} \mathrm{C} \mathrm{NMR}\left(101 \mathrm{MHz}, \mathrm{CD}_{3} \mathrm{OD}\right) \delta 172.60,169.15,168.77,155.98$, $137.14,133.09,132.71,130.35,129.96,128.97,128.24,127.24,127.12,125.69,123.61,122.92,115.84,112.69$, $66.75,57.13,57.05,55.45,54.80,39.42,37.92,32.43,30.44,28.31,27.16,25.87,24.07,15.25,14.88$; HRMS (ESI) calc'd for $\mathrm{C}_{34} \mathrm{H}_{45} \mathrm{~N}_{5} \mathrm{O}_{4}: 588.3544$, found 588.3539.<smiles>O=C(Cl)CCCCCCCCCCCNC(=O)F</smiles>

Step 1: (9H-Fluoren-9-yl)methyl (12-chloro-12-oxododecyl)carbamate

Under nitrogen, to a solution of 12-((( (9H-fluoren-9-yl)methoxy)carbonyl)amino)dodecanoic acid (960 mg, 2.19 $\mathrm{mmol})$ in dichloromethane $(8 \mathrm{~mL})$ was added oxalyl dichloride $(310 \mathrm{mg}, 2.44 \mathrm{mmol})$ and N,N-dimethylformamide $(0.1 \mathrm{~mL}, 1.292 \mathrm{mmol})$ dropwise at $0^{\circ} \mathrm{C}$. The resulting solution was stirred for $1 \mathrm{~h}$ at room temperature and used directly for next operation. 


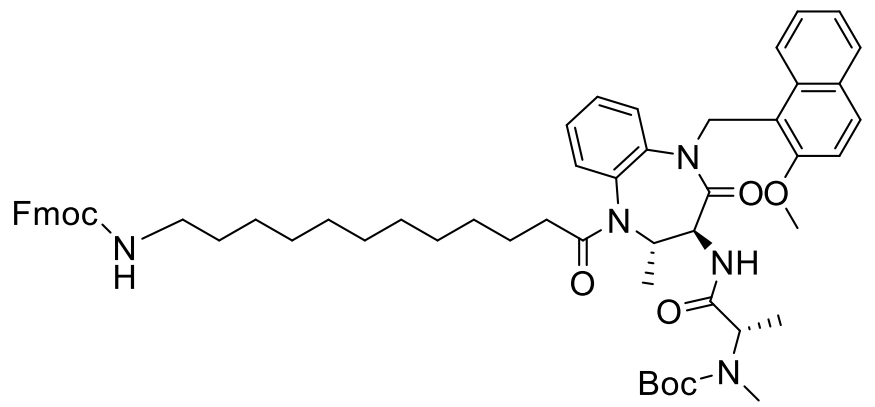

Step 2: tert-Butyl ((S)-1-(((2S,3S)-1-(12-((( $9 H$-fluoren-9-yl)methoxy)carbonyl)amino)dodecanoyl)-5-((2methoxynaphthalen-1-yl)methyl)-2-methyl-4-oxo-2,3,4,5-tetrahydro-1H-benzo[b][1,4]diazepin-3-yl)amino)-1oxopropan-2-yl)(methyl)carbamate (23)

Under nitrogen, to a solution of $17(400 \mathrm{mg}, 0.732 \mathrm{mmol})$ in dichloromethane $(10 \mathrm{~mL})$ was added a solution of (9H-fluoren-9-yl)methyl (12-chloro-12-oxododecyl)carbamate prepared from previous operation and pyridine (344 mg, $4.35 \mathrm{mmol}$ ) at $0^{\circ} \mathrm{C}$. The resulting solution was stirred at room temperature for $3 \mathrm{~h}$. The reaction system was diluted with water, extracted with dichloromethane. The combined organic layers were dried over anhydrous sodium sulfate and concentrated under vacuum. The residual was purified by flash chromatography on silica gel eluting with EtOAc/petroleum ether (0 70\%) to afford the title compound $450 \mathrm{mg}(64 \%)$ as a white solid. LC-MS (ESI, m/z): $[\mathrm{M}+\mathrm{H}]^{+}=966$

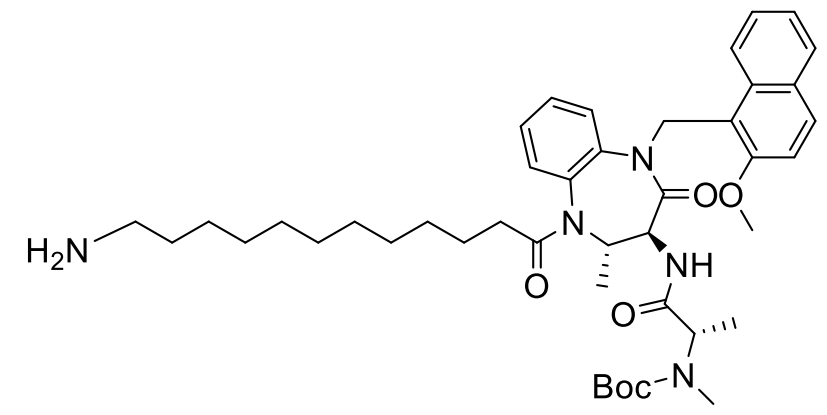

Step 3: tert-Butyl ((S)-1-(((2S,3S)-1-(12-aminododecanoyl)-5-((2-methoxynaphthalen-1-yl)methyl)-2-methyl-4oxo-2,3,4,5-tetrahydro-1H-benzo[b][1,4]diazepin-3-yl)amino)-1-oxopropan-2-yl)(methyl)carbamate (29)

Under nitrogen, to a solution of $23(430 \mathrm{mg}, 0.445 \mathrm{mmol})$ in dichloromethane $(5 \mathrm{~mL})$ was added DBU (140 mg, $0.920 \mathrm{mmol}$,$) . The resulting solution was stirred for 2 \mathrm{~h}$ at room temperature. The solvent was removed under vacuum. The crude product was purified by flash chromatography on silica gel eluting with methanol/DCM $\left(0^{\sim 15 \%)}\right.$ to afford the title compound $220 \mathrm{mg}(66 \%)$ as a white solid. $\mathrm{LC}-\mathrm{MS}(\mathrm{ESI}, \mathrm{m} / \mathrm{z}):[\mathrm{M}+\mathrm{H}]^{+}=744$

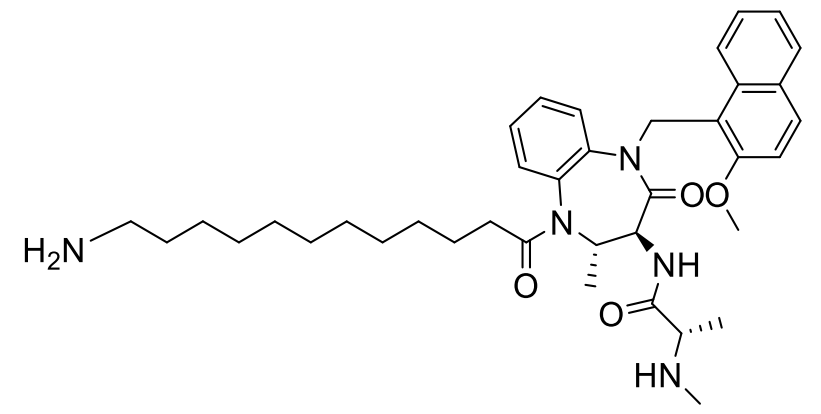

Step 4: (S)-N-((2S,3S)-1-(12-Aminododecanoyl)-5-((2-methoxynaphthalen-1-yl)methyl)-2-methyl-4-oxo-2,3,4,5tetrahydro-1H-benzo[b][1,4]diazepin-3-yl)-2-(methylamino)propenamide (11)

To a solution of 29 (50 mg, $0.067 \mathrm{mmol})$ in dichloromethane $(1 \mathrm{~mL})$ was added $\mathrm{HCl} /$ dioxane $(2 \mathrm{~mL}, 4 \mathrm{M})$. The resulting solution was stirred for $1 \mathrm{~h}$ at room temperature. The resulting mixture was concentrated under vacuum. The crude product was purified by Prep-HPLC with the following conditions (Column, XBridge Prep C18 
OBD Column, ,5um,19*150mm; mobile phase, Waters(0.1\%FA) and ACN (25\% ACN to 50\% in 8 min); Detector, UV 254/220nm) to afford the title compound $14 \mathrm{mg}(32 \%)$ as a white solid. LC-MS (ESI, $\mathrm{m} / \mathrm{z}):[\mathrm{M}+\mathrm{H}]^{+}=644 ;{ }^{1} \mathrm{H}$ NMR $(300 \mathrm{MHz}$, DMSO-d $) \delta 8.52(\mathrm{~d}, J=9.1 \mathrm{~Hz}, 1 \mathrm{H}), 8.41(\mathrm{~s}, 1 \mathrm{H}), 8.15-7.99(\mathrm{~m}, 1 \mathrm{H}), 7.90(\mathrm{dd}, J=8.2,1.4 \mathrm{~Hz}$, $1 \mathrm{H}), 7.83-7.68(\mathrm{~m}, 2 \mathrm{H}), 7.52(\mathrm{td}, J=7.6,1.5 \mathrm{~Hz}, 1 \mathrm{H}), 7.43-7.27(\mathrm{~m}, 3 \mathrm{H}), 7.05(\mathrm{dd}, J=7.8,1.4 \mathrm{~Hz}, 1 \mathrm{H}), 5.94(\mathrm{~d}$, $J=14.7 \mathrm{~Hz}, 1 \mathrm{H}), 5.33(\mathrm{~d}, J=14.7 \mathrm{~Hz}, 1 \mathrm{H}), 4.78(\mathrm{dq}, J=12.4,6.1 \mathrm{~Hz}, 1 \mathrm{H}), 4.20-3.82(\mathrm{~m}, 5 \mathrm{H}), 3.04(\mathrm{q}, J=6.8 \mathrm{~Hz}$, $1 \mathrm{H}), 2.74(\mathrm{t}, J=7.0 \mathrm{~Hz}, 2 \mathrm{H}), 2.23(\mathrm{~s}, 3 \mathrm{H}), 1.52(\mathrm{q}, J=7.4 \mathrm{~Hz}, 2 \mathrm{H}), 1.41-1.00(\mathrm{~m}, 13 \mathrm{H}), 1.00-0.76(\mathrm{~m}, 7 \mathrm{H}), 0.51$ $(\mathrm{td}, J=16.7,7.9 \mathrm{~Hz}, 2 \mathrm{H}), 0.32(\mathrm{tq}, J=10.5,5.4,4.8 \mathrm{~Hz}, 1 \mathrm{H}),-0.57$ (ddd, $J=15.6,10.8,4.7 \mathrm{~Hz}, 1 \mathrm{H})$.

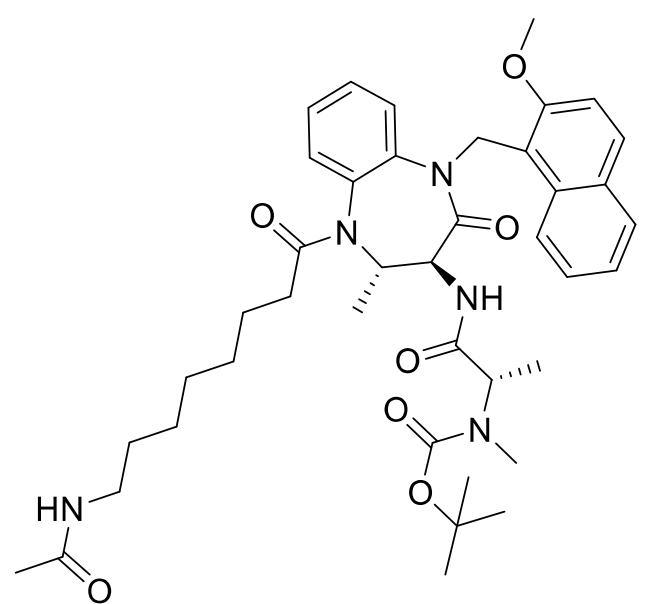

tert-butyl ( $\quad(S)$-1-(( $2 S, 3 S)$-1-(8-acetamidooctanoyl)-5-((2-methoxynaphthalen-1-yl)methyl)-2-methyl-4-oxo2,3,4,5-tetrahydro-1H-benzo[b][1,4]diazepin-3-yl)amino)-1-oxopropan-2-yl)(methyl)carbamate (30)

tert-butyl-N-[(1S)-2-[[(3S,4S)-5-(8-aminooctanoyl)-1-[(2-methoxy-1-naphthyl)methyl]-4-methyl-2-oxo-3,4dihydro-1,5-benzodiazepin-3-yl]amino]-1-methyl-2-oxo-ethyl]-N-methyl-carbamate (28) (10.4 mg, 0.0151 $\mathrm{mmol}$ ) was dissolved in dichloromethane, cooled to OC, treated with triethylamine (3 equiv., $0.0454 \mathrm{mmol}$, $0.00632 \mathrm{~mL}$ ) and acetic anhydride (1.2 equiv., $0.0181 \mathrm{mmol}, 0.00171 \mathrm{~mL}$ ) and stirred at room temperature overnight. LCMS indicated the reaction completed. The reaction mixture was concentrated under vacuum, yielding $11 \mathrm{mg}$ of product. LCMS (ESI, $\mathrm{m} / \mathrm{z}):[\mathrm{M}+\mathrm{H}]^{+} 731$.

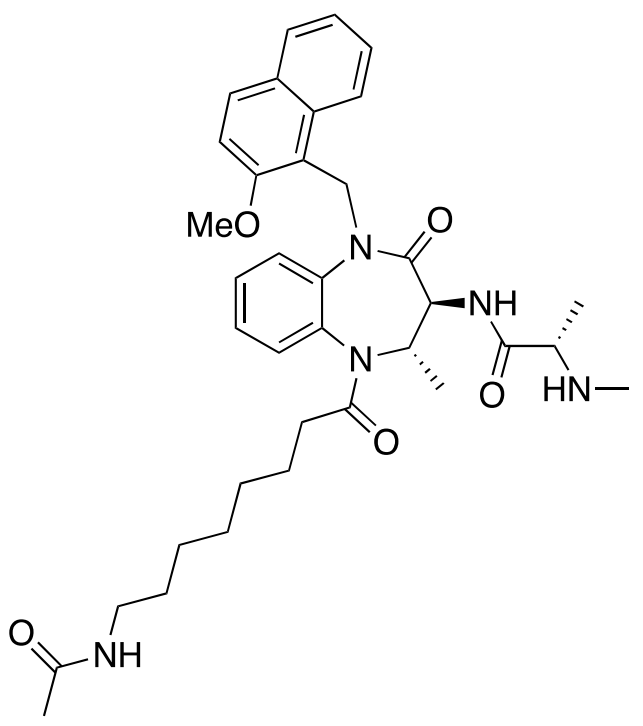

(S)-N-((2S,3S)-1-(8-acetamidooctanoyl)-5-((2-methoxynaphthalen-1-yl)methyl)-2-methyl-4-oxo-2,3,4,5tetrahydro-1H-benzo[b][1,4]diazepin-3-yl)-2-(methylamino)propenamide (12) 
Compound 30 (11.0 mg, $0.0151 \mathrm{mmol})$ was dissolved in dichloromethane $(0.3 \mathrm{~mL})$, added TFA (0.3 $\mathrm{mL})$ and stirred at room temperature for $30 \mathrm{~min}$, then concentrated under vacuum, yielding $11.2 \mathrm{mg}$ of product. LCMS $(\mathrm{ESI}, \mathrm{m} / \mathrm{z}):[\mathrm{M}+\mathrm{H}]^{+} 631$.

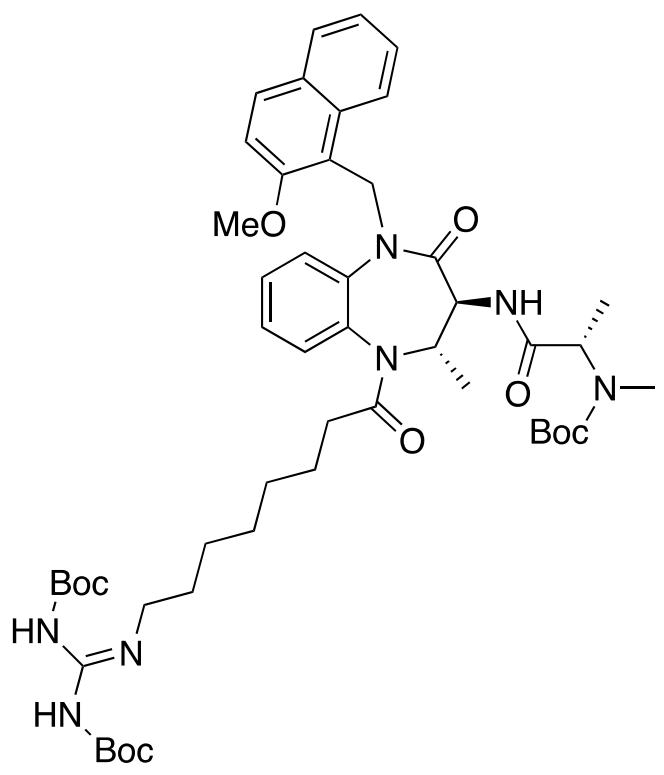

tert-butyl N-[(1S)-2-[[(3S,4S)-5-[8-[bis(tertbutoxycarbonylamino)methyleneamino]octanoyl]-1-[(2-methoxy-1naphthyl)methyl]-4-methyl-2-oxo-3,4-dihydro-1,5-benzodiazepin-3-yl]amino]-1-methyl-2-oxoethyl]-N-methylcarbamate (31)

To a suspension of $28(9.3 \mathrm{mg}, 0.014 \mathrm{mmol})$ in dichloromethane $(0.2 \mathrm{~mL})$, a solution of 1,3-di-boc-2(trifluoromethylsulfonyl)guanidine (1 equiv., $0.014 \mathrm{mmol}$ ) and triethylamine (1 equiv., $0.014 \mathrm{mmol}, 0.0019 \mathrm{~mL}$ ) in dichloromethane $(0.2 \mathrm{~mL})$ was added. The mixture was stirred at room temperature for 1 hour, until LCMS indicated reaction completion. $200 \mathrm{uL}$ of methanol was added to the mixture and stirred at room temperature for $30 \mathrm{~min}$. The reaction mixture was concentrated under vacuum via rotary evaporation. The residue was subjected to column purification via Teledyne ISCO CombiFlask Rf200i in heptane, iPrOAc in a linear gradient (0 to $100 \%$ ), yielding $10.3 \mathrm{mg}$ of product. LCMS (ESI, $\mathrm{m} / \mathrm{z}):[\mathrm{M}+\mathrm{H}]^{+} 931$.

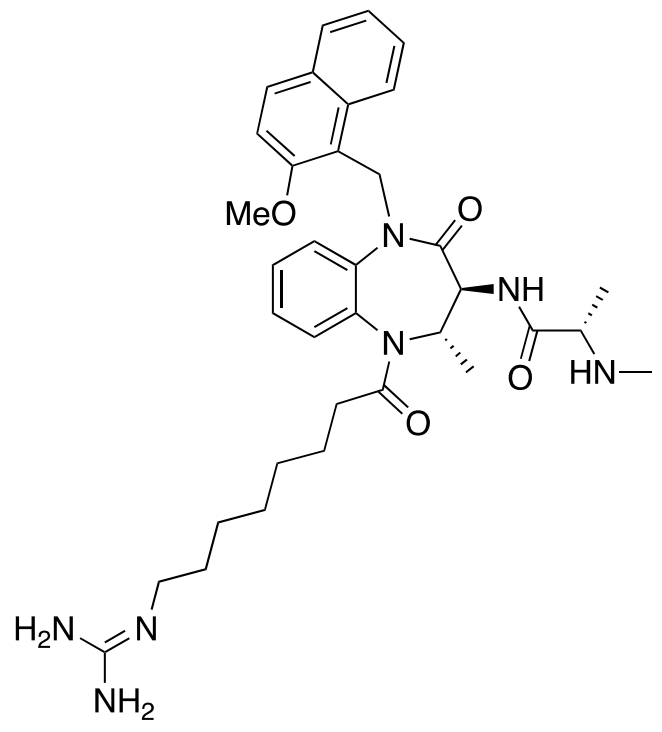

(S)-N-((2S,3S)-1-(8-((diaminomethylene)amino)octanoyl)-5-((2-methoxynaphthalen-1-yl)methyl)-2-methyl-4oxo-2,3,4,5-tetrahydro-1H-benzo[b][1,4]diazepin-3-yl)-2-(methylamino)propenamide (13) 
Compound 31 (10.3 mg) was dissolved in dichloromethane $(0.3 \mathrm{~mL})$, cooled to ${ }^{0} \mathrm{C}$, treated with $0.1 \mathrm{~mL}$ of TFA and stirred on ice for $30 \mathrm{~min}$. LCMS indicated there were still mono-, di-, and tri-deprotected compounds. The mixture was warmed to room temperature and stirred at the same temperature overnight. The mixture was concentrated in vacuo, yielding $10.8 \mathrm{mg}$ of product. LCMS $(\mathrm{ESI}, \mathrm{m} / \mathrm{z}):[\mathrm{M}+\mathrm{H}]^{+} 631$.

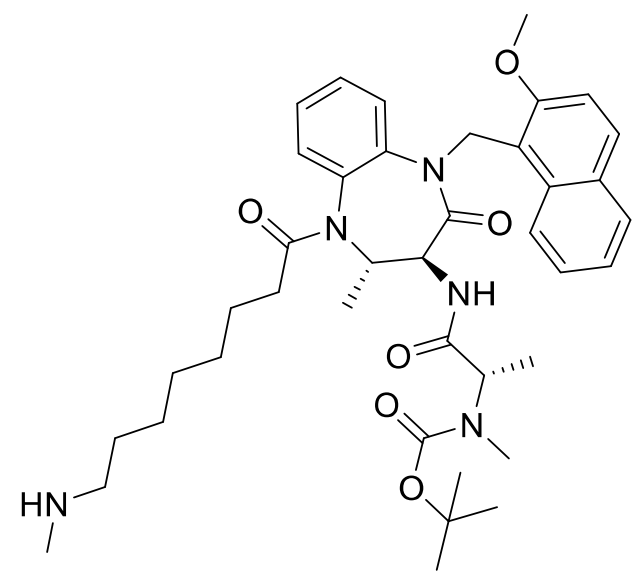

tert-butyl ((S)-1-(((3S,4S)-1-((2-methoxynaphthalen-1-yl)methyl)-4-methyl-5-(8-(methylamino)octanoyl)-2-oxo2,3,4,5-tetrahydro-1H-benzo[b][1,4]diazepin-3-yl)amino)-1-oxopropan-2-yl)(methyl)carbamate (33)

tert-butyl-N-[(1S)-2-[[(3S,4S)-5-(8-bromooctanoyl)-1-[(2-methoxy-1-naphthyl)methyl]-4-methyl-2-oxo-3,4dihydro-1,5-benzodiazepin-3-yl]amino]-1-methyl-2-oxo-ethyl]-N-methyl-carbamate (32) (14.3 mg, 0.0190 $\mathrm{mmol}$ ) was diluted in methylamine $(2 \mathrm{~mol} / \mathrm{L})$ in THF (10 equiv., $0.190 \mathrm{mmol}, 0.0951 \mathrm{~mL}$ ) at room temperature under an atmosphere of nitrogen and stirred at $5^{\circ} \mathrm{C}$ for 3 hours, until LCMS indicates reaction completion. The reaction mixture was concentrated under reduced pressure and then dissolved in dichloromethane $(500 \mathrm{~mL})$. The solution was washed with water $(3 \times 200 \mathrm{~mL})$ and brine $(200 \mathrm{~mL})$, dried over $\mathrm{MgSO}_{4}$, filtered through Celite and concentrated under reduced pressure. The product was purified by SFC, yielding 1.4 mg of pure product. LCMS (ESI, m/z): $[\mathrm{M}+\mathrm{H}]^{+} 703$.

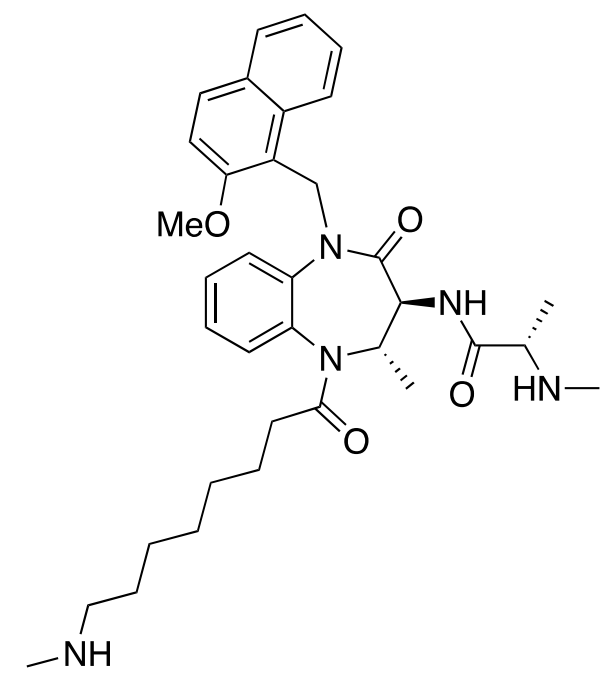

(S)-N-((3S,4S)-1-((2-methoxynaphthalen-1-yl)methyl)-4-methyl-5-(8-(methylamino)octanoyl)-2-oxo-2,3,4,5tetrahydro-1H-benzo[b][1,4]diazepin-3-yl)-2-(methylamino)propenamide (14)

Compound 33 (1.4 mg) was dissolved in dichloromethane (500 uL) and treated with TFA (500 uL). The reaction mixture was stirred at room temperature for $15 \mathrm{~min}$, until LCMS indicated the reaction was complete. The solvent was removed under vacuum and the oily residue was dried on a vacuum pump. LCMS (ESI, $\mathrm{m} / \mathrm{z}):[\mathrm{M}+$ $\mathrm{H}]^{+} 603$. 


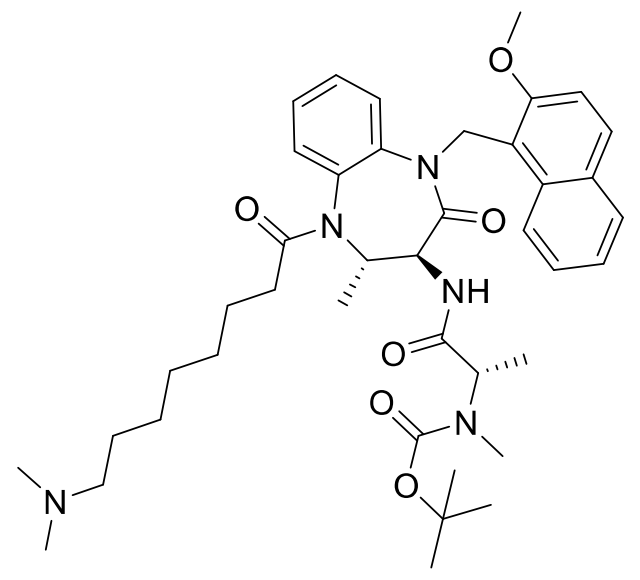

tert-butyl-N-[(1S)-2-[[(3S,4S)-5-[8-(dimethylamino)octanoyl]-1-[(2-methoxy-1-naphthyl)methyl]-4-methyl-2oxo-3,4-dihydro-1,5-benzodiazepin-3-yl]amino]-1-methyl-2-oxo-ethyl]-N-methyl-carbamate (34)

To a solution of $32(16.7 \mathrm{mg}, 0.0222 \mathrm{mmol})$ in THF $(0.05 \mathrm{~mL})$ in a pressure reaction vessel was added triethylamine ( 3.02 equiv., $0.0671 \mathrm{mmol}, 0.00935 \mathrm{~mL}$ ) and dimethylamine $(2 \mathrm{~mol} / \mathrm{L})$ in THF $(0.0333 \mathrm{~mL})$. The reaction vessel was sealed and heated to $50^{\circ} \mathrm{C}$ for 5 hours and then cooled to room temperature. The reaction mixture was then concentrated and re-dissolved in THF $(0.05 \mathrm{~mL})$, treated with triethylamine (3.02 equiv., 0.067 $\mathrm{mmol}, 0.01 \mathrm{~mL})$, dimethylamine $(2 \mathrm{~mol} / \mathrm{L})$ in THF $(0.0333 \mathrm{~mL})$ and sealed and heated again to $55^{\circ} \mathrm{C}$ for $24 \mathrm{hours}$. The reaction mixture was concentrated under reduced pressure and then dissolved in dichloromethane (500 $\mathrm{mL})$. The solution was washed with water $(3 \times 200 \mathrm{~mL})$ and brine $(200 \mathrm{~mL})$, dried over MgSO4, and filtered through Celite and concentrated under reduced pressure. The product was purified by reversed-phase HPLC, yielding $6 \mathrm{mg}$ of pure product. LCMS (ESI, m/z): [M+ H] $]^{+} 717$.

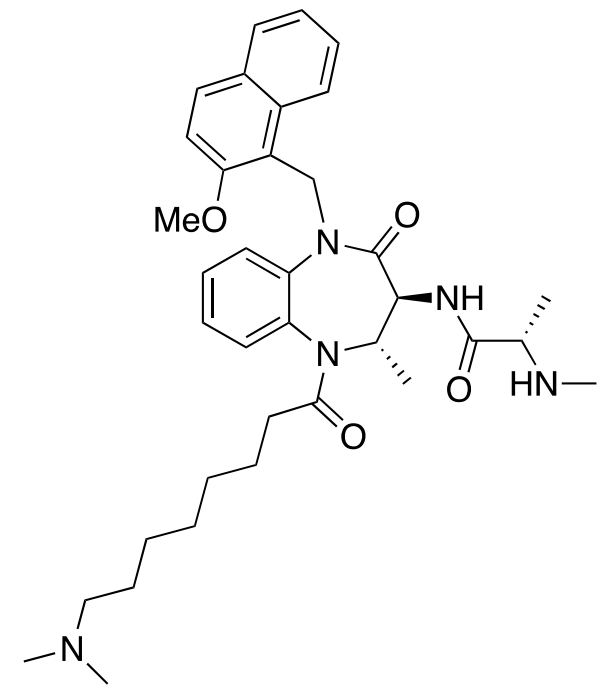

(S)-N-((2S,3S)-1-(8-(dimethylamino)octanoyl)-5-((2-methoxynaphthalen-1-yl)methyl)-2-methyl-4-oxo-2,3,4,5tetrahydro-1H-benzo[b][1,4]diazepin-3-yl)-2-(methylamino)propenamide (15)

Compound 34 was dissolved in dichloromethane $(0.2 \mathrm{~mL})$, TFA was added $(0.2 \mathrm{~mL})$ and stirred at room temperature for $10 \mathrm{~min}$. The mixture was concentrated in vacuo, yielding $6.1 \mathrm{mg}$ of product. LCMS (ESI, $\mathrm{m} / \mathrm{z}$ ): $[\mathrm{M}+\mathrm{H}]^{+} 617$. 


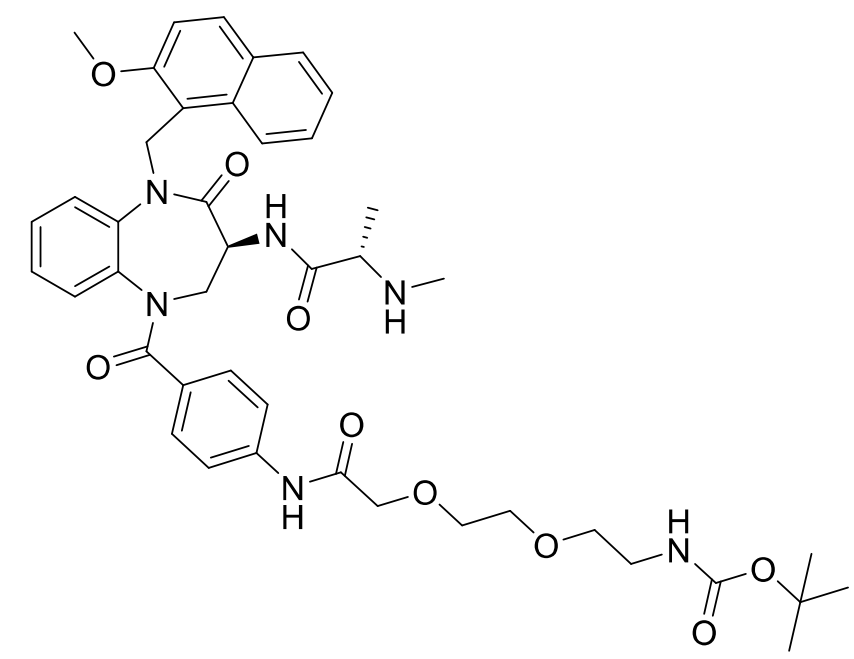

tert-butyl (2-(2-(2-)((4-((S)-5-((2-methoxynaphthalen-1-yl)methyl)-3-((S)-2-(methylamino)propanamido)-4-oxo2,3,4,5-tetrahydro-1H-benzo[ $b][1,4]$ diazepine-1-carbonyl)phenyl)amino)-2-oxoethoxy)ethoxy)ethyl)carbamate (35)

(2S)-N-[(3S)-1-(4-aminobenzoyl)-5-[(2-methoxy-1-naphthyl)methyl]-4-oxo-2,3-dihydro-1,5-benzodiazepin-3yl]-2-(methylamino)propanamide (1) $(10 \mathrm{mg}, 0.01813 \mathrm{mmol}$ ) was added to a solution of 2,2-dimethyl-4-oxo3,8,11-trioxa-5-azatridecan-13-oic acid (3 equiv., $0.05439 \mathrm{mmol})$ in water followed by the addition of [1-(3dimethylaminopropyl)-3-ethyl carbodiimide hydrochloride (EDC) (3 equiv., $0.05439 \mathrm{mmol}$ ). After the solution was stirred overnight, the reaction mixture was concentrated and added iPrOAc and saturated $\mathrm{NaHCO}_{3}$, and organic layer was separated. The aqueous layer was extracted with iPrOAc 2 more times, and combined organic layers was dried over $\mathrm{MgSO}_{4}$. The solvent was removed under vacuum (12.3 $\mathrm{mg}$ of a yellow oil). LCMS (ESI, $\mathrm{m} / \mathrm{z}$ ): $[\mathrm{M}+\mathrm{H}]^{+} 798$.<smiles>CN[C@@H](C)C(=O)N[C@H]1CN(C(=O)c2ccc(NC(=O)COCCOCCN)cc2)c2ccccc2N(Cc2c(OC)ccc3ccccc23)C1=O</smiles>

(S)-N-((S)-5-(4-(2-(2-(2-aminoethoxy)ethoxy)acetamido)benzoyl)-1-((2-methoxynaphthalen-1-yl)methyl)-2-oxo2,3,4,5-tetrahydro-1H-benzo[b][1,4]diazepin-3-yl)-2-(methylamino)propenamide (6)

Compound 35 was dissolved in dichloromethane $(2 \mathrm{~mL})$ and treated with TFA $(2 \mathrm{~mL})$. The reaction mixture was stirred at room temperature for $15 \mathrm{~min}$, until LCMS indicated the reaction was complete. The solvent was removed under vacuum and the oily residue was dried on a vacuum pump. LCMS (ESI, m/z): [M + H] 697 . 
<smiles>CN[C@@H](C)C(=O)N[C@H]1CN(C(=O)c2ccc(NC(=O)CCCCCCCCCCNC(=O)OC(C)(C)C)cc2)C(=O)N(Cc2c(OC)ccc3ccccc23)c2ccccc21</smiles>

tert-butyl (11-((4-((S)-5-((2-methoxynaphthalen-1-yl)methyl)-3-((S)-2-(methylamino)propanamido)-4-oxo2,3,4,5-tetrahydro-1H-benzo[ $b][1,4]$ diazepine-1-carbonyl)phenyl)amino)-11-oxoundecyl)carbamate (36)

Compound 1 (10 mg, $0.01813 \mathrm{mmol}$ ) and Boc-11-aminoundecanoic acid (3 equiv., 0.05439 mmol) were dissolved in 50:50 v/v water-THF mixture. To the solution, EDC (3 equiv. $0.054 \mathrm{mmol}$ ) and stirred at room temperature for 4 hours. The reaction mixture was concentrated under vacuum and purified by reversed-phase HPLC, yielding $6.8 \mathrm{mg}$ of pure product. LCMS (ESI, $\mathrm{m} / \mathrm{z}):[\mathrm{M}+\mathrm{H}]^{+} 836$.

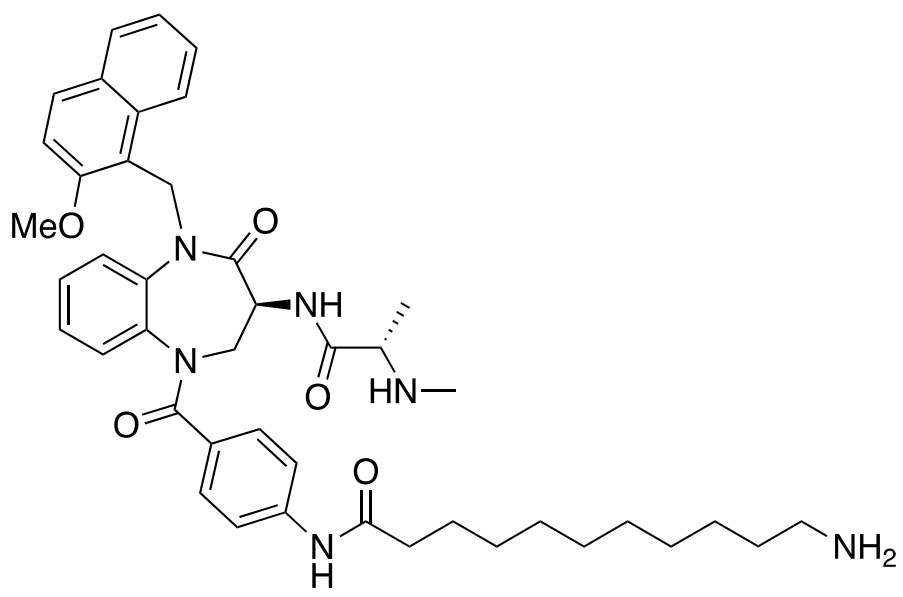

11-amino- $N$-(4-((S)-5-((2-methoxynaphthalen-1-yl)methyl)-3-((S)-2-(methylamino)propanamido)-4-oxo2,3,4,5-tetrahydro-1H-benzo[b][1,4]diazepine-1-carbonyl)phenyl)undecanamide (7)

Compound 36 was dissolved in dichloromethane $(2 \mathrm{~mL})$ and treated with TFA $(2 \mathrm{~mL})$. The reaction mixture was stirred at room temperature for $15 \mathrm{~min}$, until LCMS indicated the reaction was complete. The solvent was removed under vacuum and the oily residue was dried on a vacuum pump. LCMS (ESI, m/z): [M + H] 736 . 


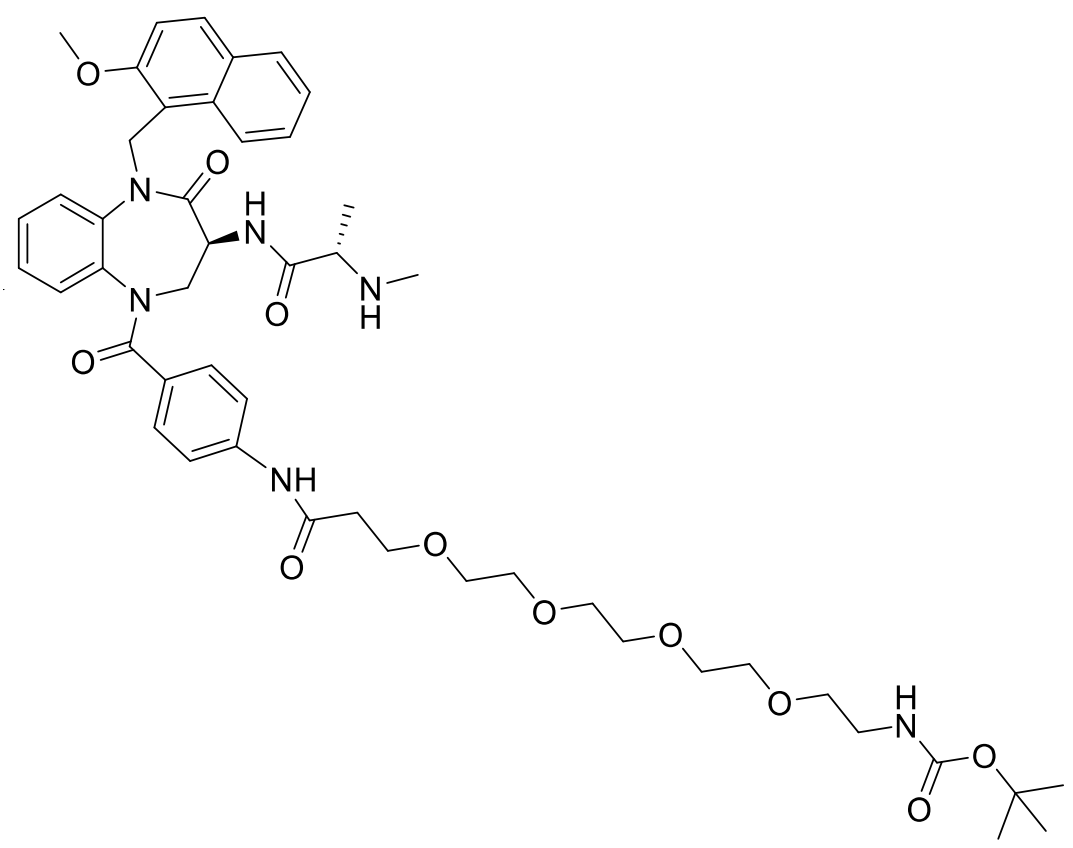

tert-butyl (15-((4-((S)-5-((2-methoxynaphthalen-1-yl)methyl)-3-((S)-2-(methylamino)propanamido)-4-oxo2,3,4,5-tetrahydro-1H-benzo[b][1,4]diazepine-1-carbonyl)phenyl)amino)-15-oxo-3,6,9,12tetraoxapentadecyl)carbamate (37)

Compound 1 (20 mg, $0.03626 \mathrm{mmol}$ ) in water was treated with 15-(Boc-amino)-4,7,10,13tetraoxapentadecanoic acid ( 3 equiv., $41.8 \mathrm{mg}$ ), followed by addition of EDC ( 3 equiv., $0.1088 \mathrm{mmol}$ ). After the solution was stirred overnight, additional PEG linker (3 equiv., $41.8 \mathrm{mg}$ ) in THF was added to the mixture and stirred at room temperature for 3 hours. The reaction mixture was concentrated and added PrOAc and saturated $\mathrm{NaHCO}_{3}$, and organic layer was separated. The aqueous layer was extracted with iPrOAc two more times, and combined organic layers was dried over $\mathrm{MgSO}_{4}$. The solvent was removed under vacuum. The crude product was purified by reversed-phase HPLC, yielding $10.4 \mathrm{mg}$ of pure product. LCMS (ESI, m/z): $[\mathrm{M}+\mathrm{H}]^{+} 900$.

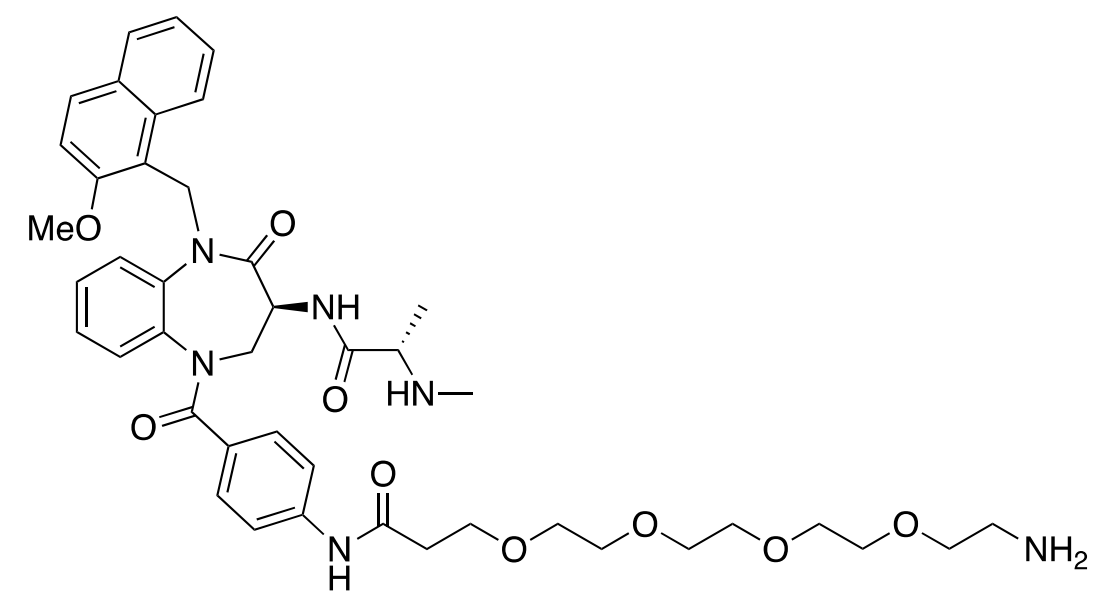

1-amino- $N$-(4-((S)-5-((2-methoxynaphthalen-1-yl)methyl)-3-((S)-2-(methylamino)propanamido)-4-oxo-2,3,4,5tetrahydro-1H-benzo[b][1,4]diazepine-1-carbonyl)phenyl)-3,6,9,12-tetraoxapentadecan-15-amide (8)

Compound 37 (10.4 mg, $0.0116 \mathrm{mmol})$ was dissolved in dichloromethane $(2 \mathrm{~mL})$, and added TFA $(2 \mathrm{~mL})$ and stirred at room temperature for $15 \mathrm{~min}$. The reaction completion was confirmed by LCMS. The solvent was removed under vacuum and dried by vacuum pump, yielding $5 \mathrm{mg}$ of crude product. LCMS (ESI, $\mathrm{m} / \mathrm{z}):[\mathrm{M}+\mathrm{H}]^{+}$ 800. 


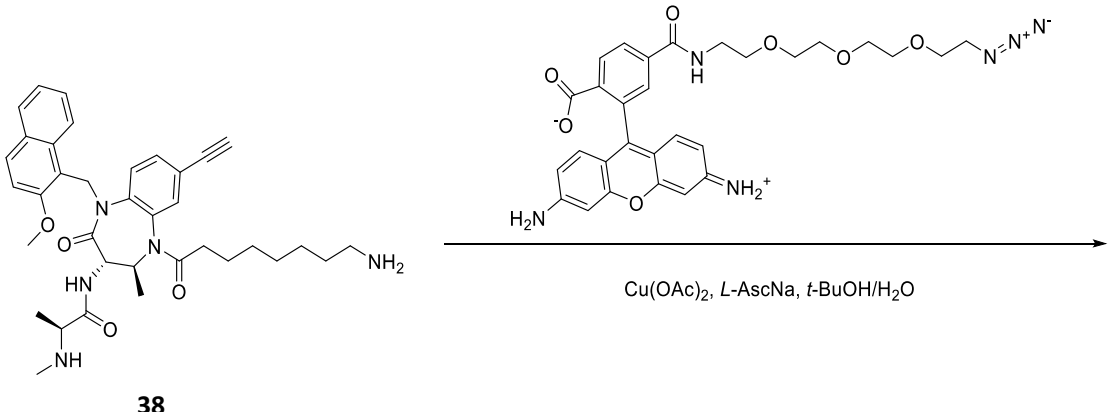

38

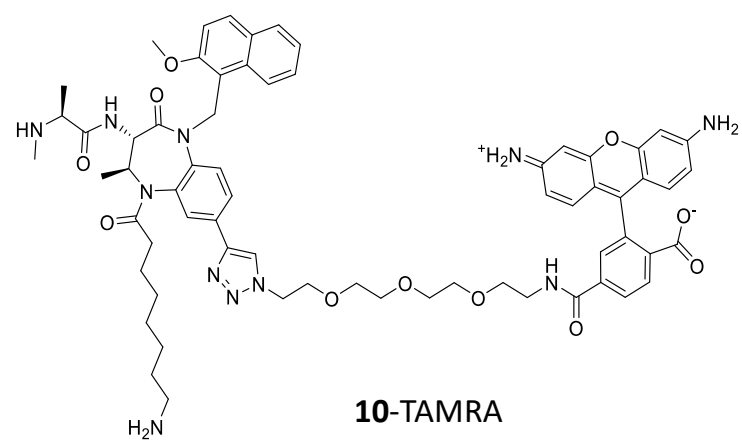

2-(6-amino-3-iminio-3H-xanthen-9-yl)-4-((2-(2-(2-(2-(4-)((3S,4S)-5-(8-aminooctanoyl)-1-((2-

methoxynaphthalen-1-yl)methyl)-4-methyl-3-((S)-2-(methylamino)propanamido)-2-oxo-2,3,4,5-tetrahydro- $1 \mathrm{H}$ benzo[b][1,4]diazepin-7-yl)-1H-1,2,3-triazol-1-yl)ethoxy)ethoxy)ethoxy)ethyl)carbamoyl)benzoate (10-TAMRA)

A solution of ((S)-N-((3S,4S)-5-(8-aminooctanoyl)-7-ethynyl-1-((2-methoxynaphthalen-1-yl)methyl)-4-methyl-2oxo-2,3,4,5-tetrahydro-1H-benzo[b][1,4]diazepin-3-yl)-2-(methylamino)propanamide $(10.0 \mathrm{mg}, 0.016 \mathrm{mmol}$, G03159372), L-AscNa $\quad(0.7 \mathrm{mg}, \quad 0.0035 \mathrm{mmol}), \quad 2-(6$-amino-3-iminio-3H-xanthen-9-yl)-4-((2-)(2-(2-(2azidoethoxy)ethoxy)ethoxy)ethyl)carbamoyl)benzoate $\left(9.4 \mathrm{mg}, 0.016 \mathrm{mmol}\right.$, commercially), and $\mathrm{Cu}(\mathrm{OAc})_{2}(0.3$ $\mathrm{mg}, 0.0015 \mathrm{mmol})$ in $t$-BuOH $(0.8 \mathrm{~mL})$ and water $(0.8 \mathrm{~mL})$ was stirred for $30 \mathrm{~min}$ at room temperature. The solvent was concentrated under vacuum. The resulting residue was purified by Prep-HPLC (conditions: Column: XSelect CSH Prep C18 OBD Column, 19×250mm, 5um; Mobile Phase A:Water(10 mmol/L NH $\left.4 \mathrm{HCO}_{3}\right), \mathrm{Mobile}$ Phase B: ACN; Flow rate: $20 \mathrm{~mL} / \mathrm{min}$; Gradient: $27 \%$ B to $50 \%$ B in $8 \mathrm{~min} ; 254,220 \mathrm{~nm}$; Rt: $5.72 \mathrm{~min}$ ) to yield 3.5 $\mathrm{mg}(17 \%)$ of the title compound as a red solid. $[\mathrm{M}+\mathrm{H}]^{+}=1187$.
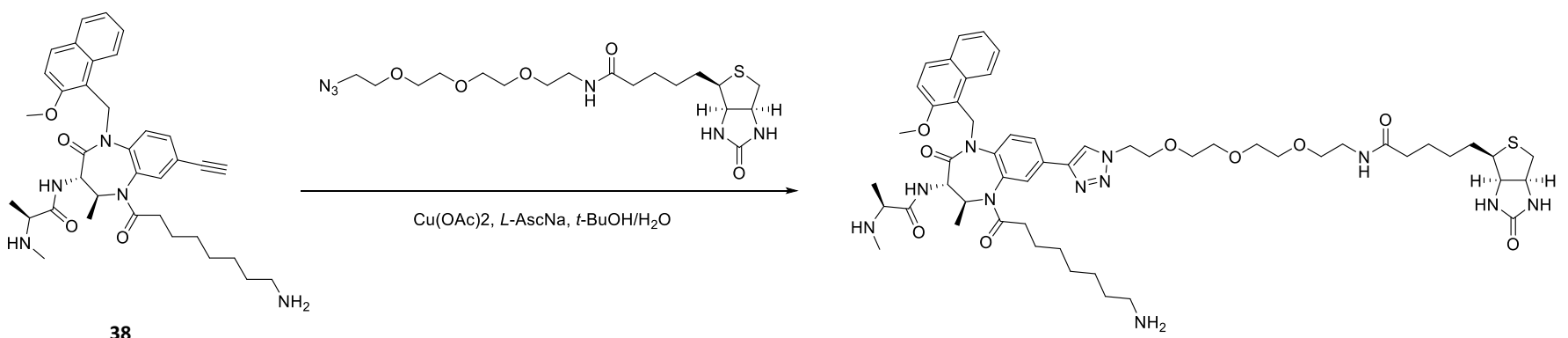

10-biotin

N-(2-(2-(2-(2-(4-((3S,4S)-5-(8-Aminooctanoyl)-1-((2-methoxynaphthalen-1-yl)methyl)-4-methyl-3-((S)-2(methylamino)propanamido)-2-oxo-2,3,4,5-tetrahydro-1H-benzo[b][1,4]diazepin-7-yl)-1H-1,2,3-triazol-1yl)ethoxy)ethoxy)ethoxy)ethyl)-5-((3aR,4R,6aS)-2-oxohexahydro-1H-thieno[3,4-d]imidazol-4-yl)pentanamide (10-biotin)

A solution of $(S)-N-((3 S, 4 S)-5-(8-a m i n o o c t a n o y l)-7-e t h y n y l-1-((2-m e t h o x y n a p h t h a l e n-1-y l) m e t h y l)-4-m e t h y l-2-$ oxo-2,3,4,5-tetrahydro-1H-benzo[b][1,4]diazepin-3-yl)-2-(methylamino)propanamide $(15.0 \mathrm{mg}, 0.025 \mathrm{mmol}) \mathrm{N}$ (2-(2-(2-(2-azidoethoxy)ethoxy)ethoxy)ethyl)-5-((3aR,4R,6aS)-2-oxohexahydro-1H-thieno[3,4-d]imidazol-4-

yl)pentanamide (10.9 mg, $0.025 \mathrm{mmol})$ sodium L-ascorbate $(1.0 \mathrm{mg}, 0.005 \mathrm{mmol})$ and $\mathrm{Cu}(\mathrm{OAc})_{2}(0.5 \mathrm{mg}, 0.002$ $\mathrm{mmol})$ in water $(0.6 \mathrm{~mL})$ and $t-\mathrm{BuOH}(0.6 \mathrm{~mL})$ was stirred for $30 \mathrm{~min}$ at room temperature. The solvent was concentrated under vacuum. The resulting residue was purified by Flash-Prep-HPLC (conditions: Column: XBridge Prep C18 OBD Column 19×150mm 5um; Mobile Phase A: Water(10 mmol/L NH $\left.4 \mathrm{HCO}_{3}\right)$, Mobile Phase B: ACN; Flow rate: 20 mL/min; Gradient: $20 \%$ B to 55\% B in 7 min; 254, $220 \mathrm{~nm}$; Rt: $6.32 \mathrm{~min}$ ) to yield $11.3 \mathrm{mg}$ (44\%) of the title compound as a green solid. LCMS (ESI): $[\mathrm{M}+\mathrm{H}]^{+}=1057$. 


\subsection{Analytical spectra for compound 10}

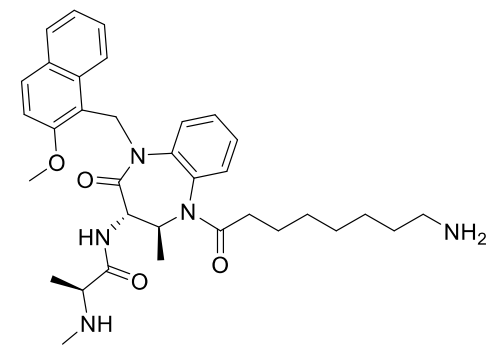

10

mAU

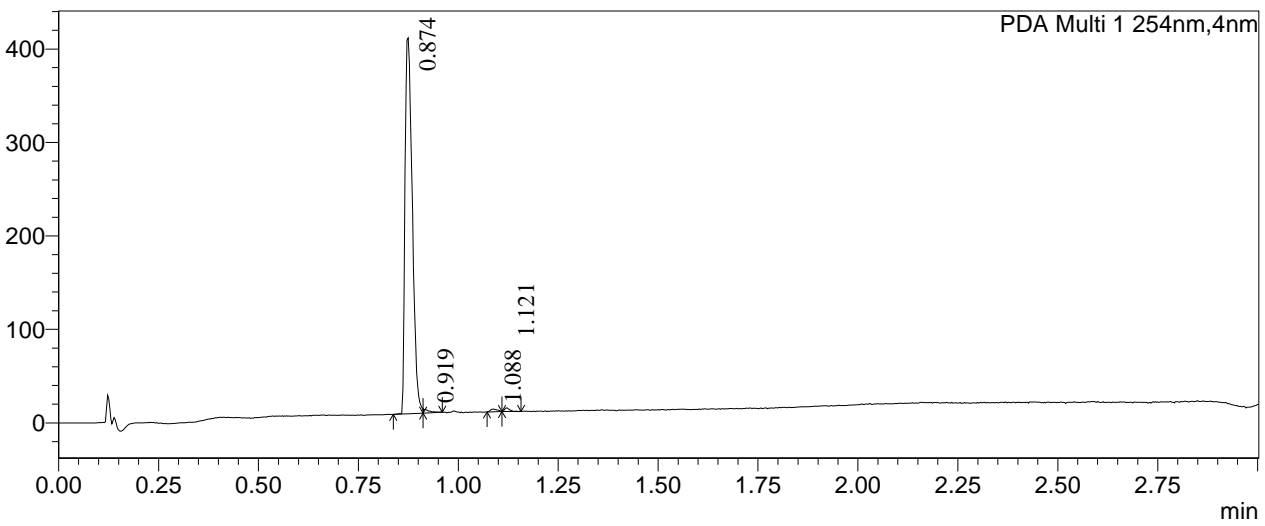

Peak Table

\begin{tabular}{|c|c|c|c|c|c|}
\hline Peak\# & Ret. Time & Height & Height\% & Area & Area\% \\
\hline 1 & 0.874 & 401080 & 97.625 & 514296 & 97.963 \\
\hline 2 & 0.919 & 3729 & 0.908 & 4018 & 0.765 \\
\hline 3 & 1.088 & 2658 & 0.647 & 3475 & 0.662 \\
\hline 4 & 1.121 & 3372 & 0.821 & 3200 & 0.610 \\
\hline Total & & 410840 & 100.000 & 524989 & 100.000 \\
\hline
\end{tabular}

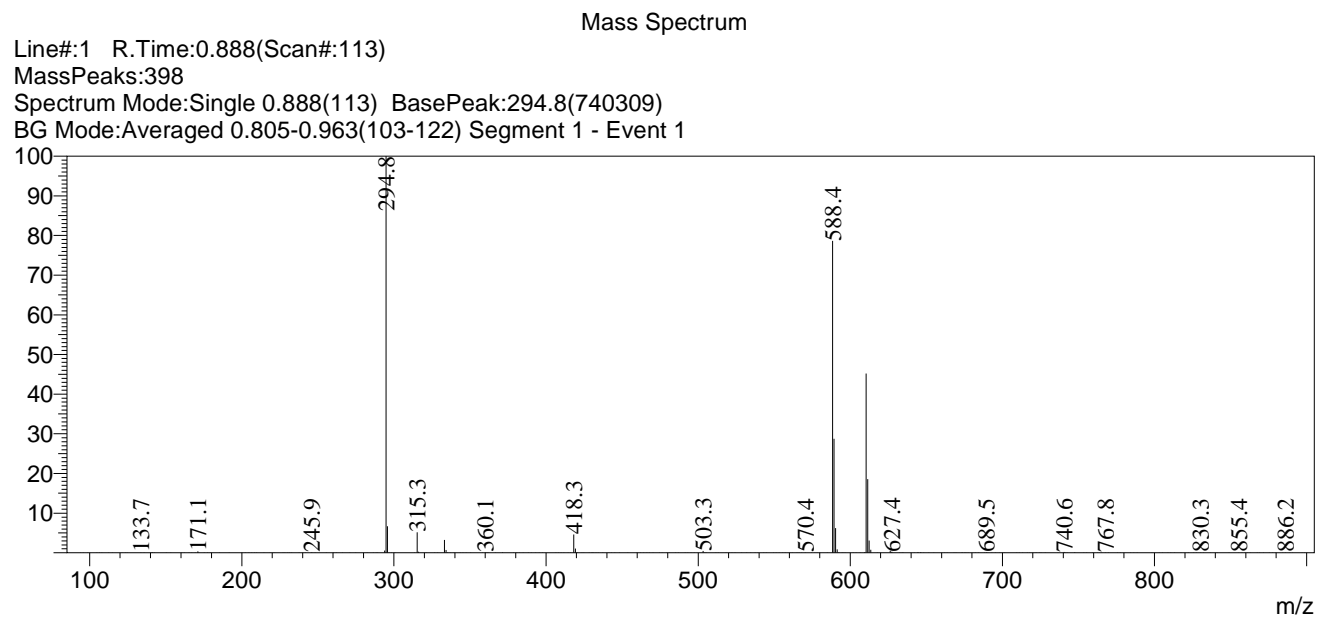




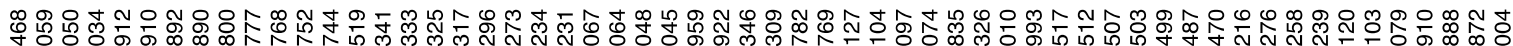

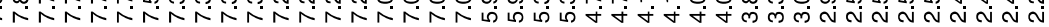
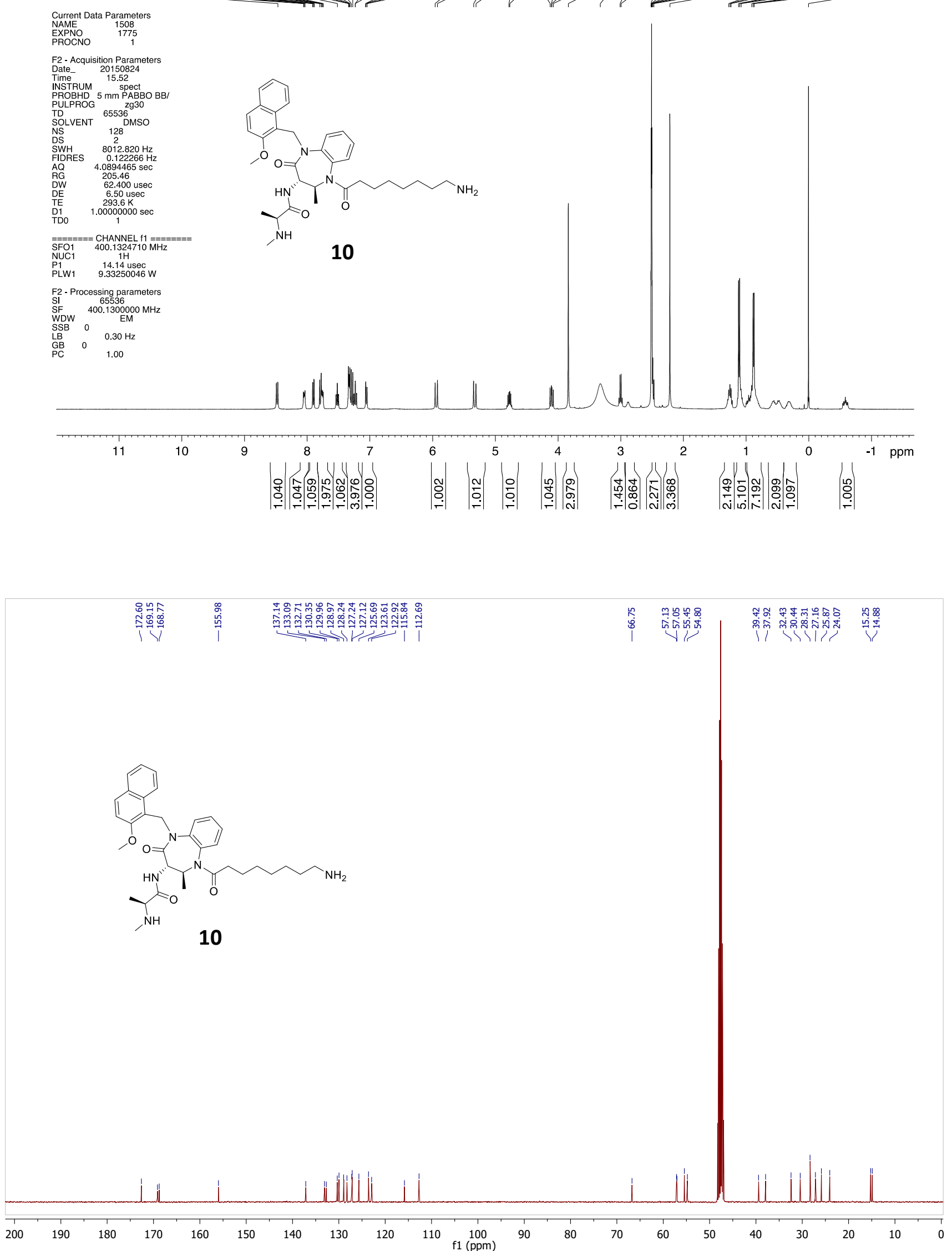

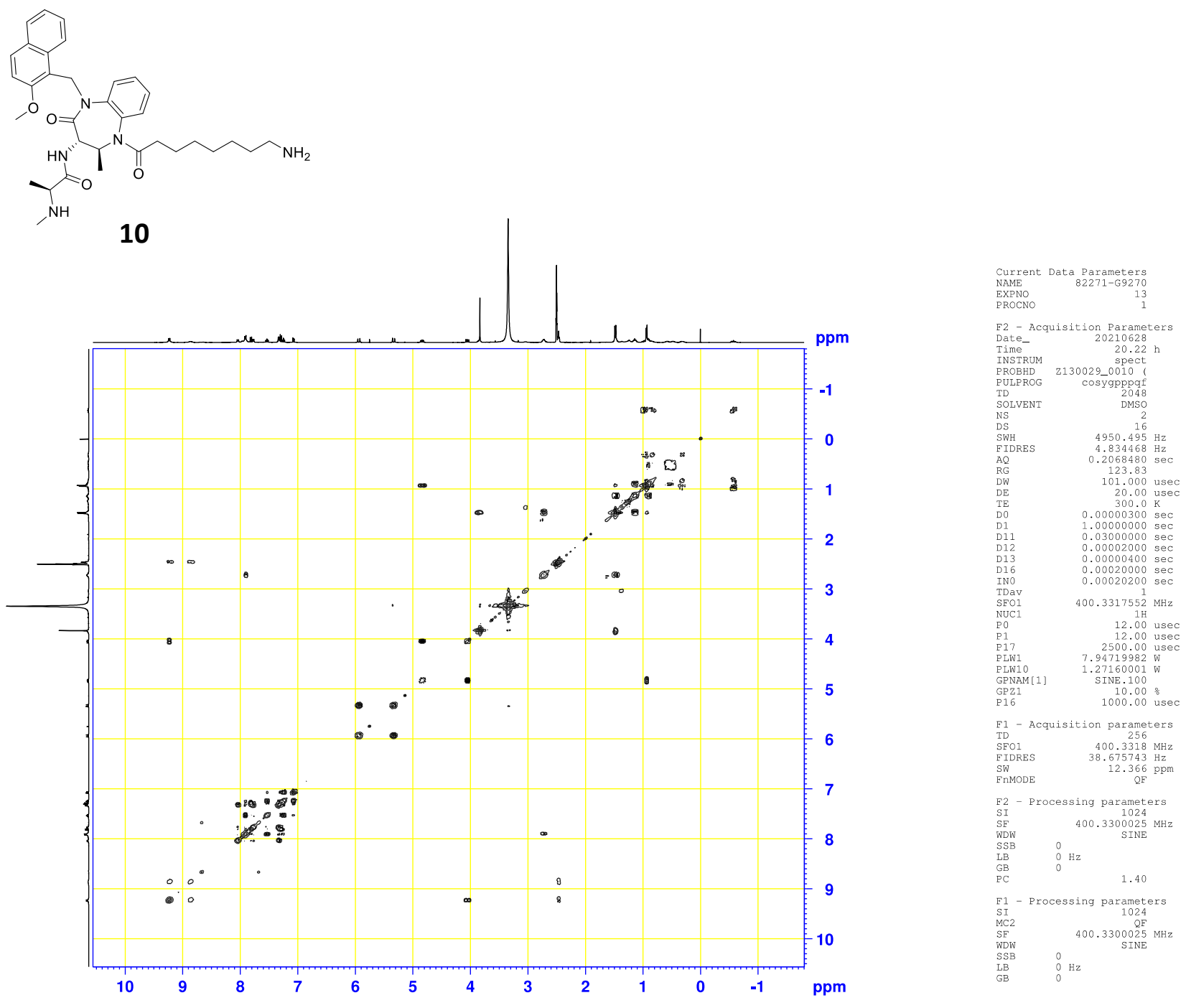